BANCA D'ITALIA

E U R O S I S T E M A

Questioni di Economia e Finanza

(Occasional Papers)

How the labour market evaluates Italian universities

by Emanuele Ciani and Vincenzo Mariani 

13 BANCA D'ITALIA

E U ROS I S T E M A

\section{Questioni di Economia e Finanza}

(Occasional papers)

How the labour market evaluates Italian universities

by Emanuele Ciani and Vincenzo Mariani

Number 247 - November 2014 
The series Occasional Papers presents studies and documents on issues pertaining to the institutional tasks of the Bank of Italy and the Eurosystem. The Occasional Papers appear alongside the Working Papers series which are specifically aimed at providing original contributions to economic research.

The Occasional Papers include studies conducted within the Bank of Italy, sometimes in cooperation with the Eurosystem or other institutions. The views expressed in the studies are those of the authors and do not involve the responsibility of the institutions to which they belong.

The series is available online at www.bancaditalia.it.

ISSN $1972-6627$ (print)

ISSN 1972-6643 (online)

Printed by the Printing and Publishing Division of the Bank of Italy 


\title{
HOW THE LABOUR MARKET EVALUATES ITALIAN UNIVERSITIES
}

\author{
by Emanuele Ciani* and Vincenzo Mariani**
}

\begin{abstract}
We analyse how the labour market implicitly evaluates Italy's higher education system by estimating differences in employment and earnings across universities. We use our estimates to produce three rankings of universities based, respectively, on employment, earnings and employment-weighted earnings. By controlling for a large set of covariates, we isolate each university effect on employment and earnings from additional components influencing graduates' labour market outcomes, namely the university's field of specialization, the graduates' observable characteristics and their local labour markets. To account for the latter, we include graduates' employment rate in the region of residence among the covariates but we instrument it with prior residence in order to correct for endogenous sorting. We discuss pros and cons of our methodology and compare our results with other available university rankings.
\end{abstract}

JEL Classification: I23, J24, J31.

Keywords: university ranking, higher education, labour market.

\section{Contents}

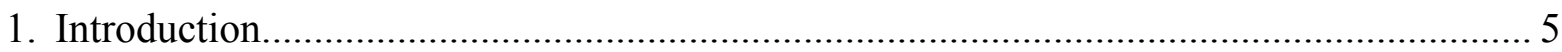

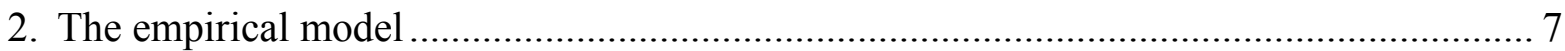

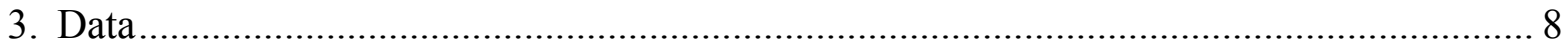

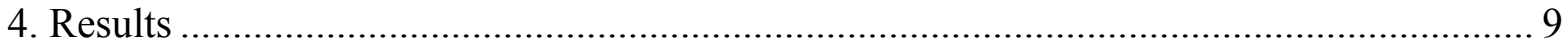

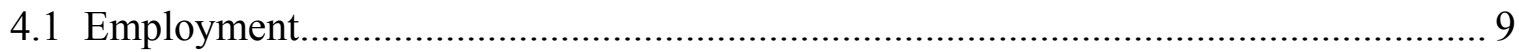

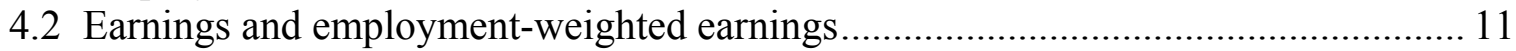

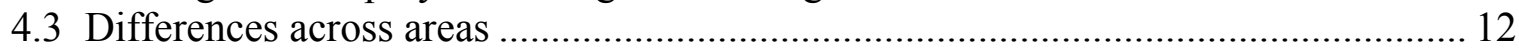

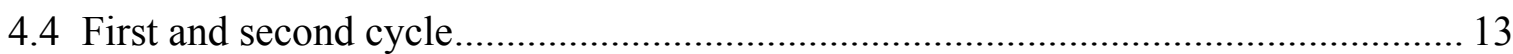

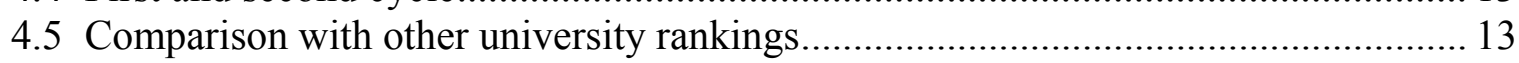

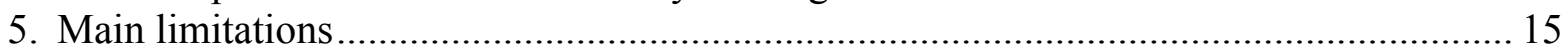

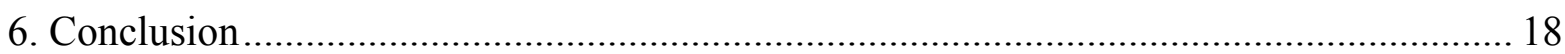

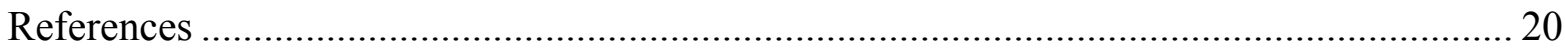

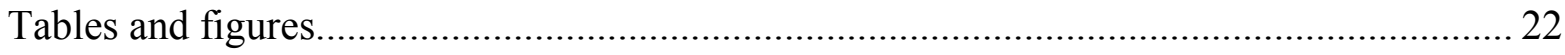

\footnotetext{
* Bank of Italy, Economic Research Unit, Florence Branch..

** Bank of Italy, Economic Research Unit, Bari Branch.
} 



\section{Introduction ${ }^{1}$}

In this paper we estimate how having a degree from a certain university influences graduates' employment rates and earnings. Using the last available wave of the Italian Survey on University Graduates' Vocational Integration (Indagine Istat sull'Inserimento Professionale dei Laureati, hereafter IIPL), we correct raw employment and earnings differentials across universities for differences in graduates' observable characteristics. To do so, we first estimate linear models with university dummies and vectors of additional covariates. We then use predictions of employment rates and earnings from our models to produce a series of university rankings. Our main aim is to assess the feasibility of using data on graduates' labour market outcomes in order to evaluate each academic institution.

Italian universities have enjoyed substantially greater autonomy since the 1990s. Decentralization has involved teaching, budgetary matters and, to some extent, recruitment policies. This process has increased the need for accountability, drawing attention to the evaluation of universities' outcomes, particularly those regarding their graduates.

Evaluation reduces the information disadvantage of stakeholders. It allows prospective students to assess appropriately the costs and benefits of attending a given university, and enables public and private financiers to allocate resources more efficiently, directing their investment towards better or improving universities. It also represents a first step to implementing incentive schemes for academic and administrative personnel. Finally, publication of the evaluation results creates a form of social pressure for a more efficient use of the available resources (Fondazione Agnelli, 2013).

Despite the consensus on the importance of evaluation, just what should be evaluated is less clear. There is no single object of analysis that can deliver all the information needed for a meaningful evaluation. For primary and secondary education, there are student achievement tests, whose results show Italian students at a disadvantage compared with their peers in similar countries and reveal striking differences within Italy (OECD, 2014). ${ }^{2}$ By contrast,

\footnotetext{
${ }^{1}$ The views expressed in this paper do not necessarily reflect the one those of the Bank of Italy. We are very grateful to Efy Adamopoulou, Raffaello Bronzini, Francesco Franceschi, Patrizia Luongo, Pasqualino Montanaro, Roberto Nisticò, Paolo Sestito, Roberto Torrini and to an anonymous referee for helpful comments. All errors are our responsibility.

${ }^{2}$ Examples of evaluations based on test scores are found, for Italy, in Cipollone et al. (2010) and Braga and Checchi (2010). For a discussion of the problems with using them, see Coe and Fitz-Gibbon (1998) and
} 
comparable measures of university graduates' achievement are not available at international level or within Italy. However, other outcomes are measurable. Italy's National Agency for the Evaluation of Universities and Research Institutes (ANVUR) recently conducted an extensive evaluation exercise covering each university research activity. The aim was to reward better performing universities with additional public resources, a common practice in many European countries. ${ }^{3}$ The media and international research centres also collect data from a wide set of sources to draw up league tables.

This paper, focusing on Italy, contributes to the literature measuring the quality of tertiary education. Our work differs from most of that literature, which is dominated by league tables, in two main respects. First, we elaborate our rankings using micro data on graduates' employment and earnings, which are among the most important outcomes of tertiary education. In the literature, it is widely recognized that labour market outcomes may be affected by university quality. The evidence, which is dominated by US and UK studies, shows that quality has a positive effect on graduates' earnings, especially in some fields (McGuinness, 2003), and a negative effect on the probability of being over-educated (Robst, 1995).

Second, our work is methodologically different. We obtain our estimates from standard econometric models: as we use a formal structure, it is easier to discuss the implications of our assumptions and their limitations, a matter often left behind in the construction of league tables indicators. Furthermore, league tables mostly reflect the contribution of the external environment and students' characteristics (Ricci, 2008), whereas we try to separate university quality from other context factors.

From the methodological point of view, our paper resembles De Simone et al. (2009), who derive indirect measures of quality in the provision of secondary education by examining students' performance when attending a university. We apply the same principle to the transition from tertiary education to the labour market. Another related work is Brunello and Cappellari (2008), who used the 2001 wave of the IIPL. We draw on their analysis using similar measures of labour market outcomes and a comparable empirical model. But whereas their aim was to study the determinants of university quality, ours is to analyse the pros and cons of this methodology for the evaluation of universities. Moreover, we employ the last available wave of IIPL, which focuses on the vocational integration of graduates from 2007 at a distance of four years from graduation. Given that the university system was reformed in 2000 to comply with the Bologna process, this allows us to analyse results for the new degrees and to compare the estimates for first-cycle degrees with those for second-cycle degrees.

The paper is organized as follows: In Section 2 we describe the empirical model and in Section 3 we present the data used for the estimation. Section 4 presents the results.

Hanushek (2003).

${ }^{3}$ ANVUR (2013). The exercise is similar in spirit to the Research Assessment Exercise conducted by the Higher Education Funding Council for England. 
In particular, we propose three rankings based, respectively, on employment, earnings and employment-weighted earnings. In addition, we compare university employment-weighted earnings across geographic areas and cycles of study and examine how our rankings correlate with other measures of quality available for Italian universities. In Section 5 we present a more technical discussion on possible limitations of our results, together with additional robustness exercises. Section 6 concludes.

\section{The Empirical Model}

We regress labour market outcomes on a vector of university dummies and additional control variables, separately for graduates in the first cycle and graduates in the second and singlecycle degrees. In particular, we assume that the outcomes are generated by the following model, where subscripts are omitted for simplicity:

$$
y=\beta_{0}+U N \beta_{U N}+F I E L D \beta_{D}+X \beta_{X}+P O S T \beta_{P O S T}+\epsilon
$$

The main labour market outcome $y$ is the employment status of a graduate four years after graduation $(e)$, although we also present results for earnings $(w)$. We include a vector of dummies UN, one for each university but one. Our aim is to estimate consistently the vector of parameters $\beta_{U N}$, which measures the effect of having studied at a specific university with respect to the reference. Each graduate is further characterized by a vector of covariates $X$, capturing pre-determined characteristics and post-graduation choices. Moreover, we add a set of dummies (FIELD) to control for the university's field of specialization, to keep university effects from reflecting specialization in fields with peculiar labour market returns. As a first approximation, to control for the heterogeneity of local labour markets, we include among the covariates the employment rate of graduates in their region of origin (the region where they were living before enrolment, $P R E$ ) and estimate the model by OLS. As a final alternative, as shown in equation (2.1), we replace the region of origin with the region where the graduate currently (four years after graduation) lives. This variable, indicated as POST, is a better proxy of the local labour markets conditions, but is likely endogenous in our model. To address this problem, we propose an instrumental variables estimation of a regression of $y$ on $U N$, POST, FIELD and $X$, with POST instrumented by PRE. Once coefficients are estimated, we obtain predicted employment rates and earnings at university level $\widehat{y}$ and aggregate them across cycles. Finally, we multiply, for each university, predicted employment and earnings to obtain employment-weighted earnings, $E=\hat{e} \cdot \hat{w}$, which we use to construct our final ranking. 


\section{Data}

In the IIPL individuals were sampled from two distinct populations of graduates from Italian universities in 2007: those with a first-cycle degree (laurea triennale), requiring three years, and those with a second-cycle degree (laurea specialistica, requiring two years after completion of the first cycle) or a single-cycle degree (laurea lunga). ${ }^{4}$ Those still graduating with pre-reform, four-year degrees are included in the second group, because their degrees are legally equivalent to second-cycle degrees. The sample design is stratified on the basis of three characteristics: type of course, university and gender. ${ }^{5}$ Given the complex structure, we chose to use sampling weights released by Istat, which were also designed to correct, indirectly, for non-response.

The sample size is quite large, representing $17.9 \%$ of the total population for the laurea triennale and $24.4 \%$ for the higher degrees. Starting from the complete sample, we dropped all the individuals with missing covariates (1\% of the sample), together with graduates who came from abroad and those who went abroad after graduation $(4 \%) .{ }^{6}$ Finally, we also excluded small universities (fewer than 200 observations in total), because the data did not allow us to estimate their quality with sufficient precision, and online universities (3\%). Table (1) summarizes sample selection.

Our main dependent variable is a binary indicator reporting whether the individual is gainfully employed at the time of the interview. We also use earnings as an alternative dependent variable, calculating it as yearly income divided by 12 months. The number of cases of missing earnings is not negligible: among individuals who reported they were working, earnings are missing in $20.2 \%$ of the observations. In some cases, this is due to sample design, because both occasional workers and self-employed persons who worked less than 12 months were not asked about their earnings. This group accounts for $35.1 \%$ of the missing values. The remaining cases are attributable to individuals who refused to state the exact amount of their earnings. Some of them may have given an answer in terms of earnings brackets, but unfortunately Istat decided not to release these values in the data set.

The current local labour market (POST in the model) is defined as the 2010 employment rate of graduates in the region where they work, for those who are employed, and as the same rate in the region where they usually live, for those who are not employed. The region before enrolment (PRE in the model) refers to where the individual officially resided before

\footnotetext{
${ }^{4}$ The length of the degree course is nominal and only a fraction of individuals graduate on time. Although the IIPL started in 1989, we are unable to pool multiple years, because the wave we use is the first explicitly designed to take account of the new degrees introduced after the 1997 reform. Moreover, in previous waves, interviews were held three years after graduation, not four years after.

${ }^{5}$ The design differed for the two population of interest, because of a different classification of the type of course. Starting from a theoretical sample, which was oversampled to account for non-response, the inclusion of units was stopped when the target of 62,000 interviews was met. The response rate was $70.1 \%$.

${ }^{6}$ We discuss the reasons and implications of this choice in Section 5.
} 
attending university. We chose the year before the interview in order to limit the direct relation between the dependent variable and our indicator of local labour market. Note that this issue is also addressed by the proposed IV estimation.

Table (2) shows the mean for graduates of second- and single-cycle courses and for graduates of first-cycle courses. Roughly $11 \%$ of graduates have a medical specialization; $29 \%$ of graduates are specialized in scientific disciplines; $23 \%$ in humanities and $35 \%$ in social sciences. Female graduates make up almost $60 \%$ of the total sample, while graduates who are foreign nationals account for only $1 \%$. The average high-school mark is 83.3 (out of 100) for first-cycle graduates and slightly larger for the others. Graduates whose father (mother) was not employed make up $2 \%(43 \%)$ of the sample. Almost two-thirds of graduates attended an academic high school; this share increases for those who hold second-cycle or single-cycle degrees. Similarly, two-thirds of graduates worked while they attended university, but only $21 \%$ on a continuous basis. The share of graduates that did not obtain further formal certification after graduation is generally high, with the exception of first-cycle graduates who have earned or are in the process of earning a second-cycle degree course (55\%).

The average employment rate of university graduates according to region of origin is 1 percentage point lower than the same rate measured by region of work, implying a net flow of graduates to regions with better employment conditions. With respect to mobility, the most likely to enrol in a university in another geographical area are those who completed high school in the South or Islands. The share of graduates who went to a university outside their home area is $23 \%$ in the South (compared with $9 \%$ in North West; Table (3). After graduation, there is an additional outflow of graduates seeking employment: among those who attended a university in the South, 19\% moved to another area (as against 10\% in the North-West; Table (4)).

\section{Results}

\subsection{Employment}

In this section we summarize the main results using mostly graphical representation for the university predictions. These were aggregated across cycles, weighted by the number of graduates in each cycle. ${ }^{7}$

Figure (1) can be used to assess the impact of each group of variables on each university effect: it presents the change in each university's predicted employment with respect to the previously estimated specification. For instance, the yellow bar indicates the difference

\footnotetext{
${ }^{7}$ Predictions for each university are calculated as average marginal effects: for every sampled individual we calculated the prediction as if he or she went to that university, and we averaged these predictions across the entire sample using sample weights.
} 
between the value predicted for university $\mathrm{j}$ by a model including $U N$ and the variables in the FIELD block (model 2) and that predicted by a model including only $U N$ (model 1$).{ }^{8}$

Raw Employment Differentials.- We start by estimating a basic linear probability model where the employment status is regressed against a set of university dummies and a constant (model 1 in Tables (5) and (6)). The employment predictions obtained from this model are by definition equal to the average of the employment dummy within universities. Employment displays large variability, ranging from $49 \%$ (University of Sannio, Benevento) to $87 \%$ (Politecnico of Milan). The national grand mean is $72 \%$.

Specialization. - To account for specialization, in model 2 we add two sets of variables: we refer to these variables as the FIELD block in figures and tables. The first set includes 15 dummies controlling for the type of field of study, the second set includes a dummy (degree duration) that controls for the presence of single-cycle courses. According to the literature (McGuinness, 2003), university specialization contributes to the labour market outcomes of graduates. For our purpose, it may affect the results for polytechnic institutes (politecnici), which mainly for historical reasons are specialized in applied science and technology. Estimated alma mater effects for most politecnici are severely affected by the omission of these variables, as Figure (1) indicates. ${ }^{9}$ The range of employment predictions across universities shrinks by 7 percentage points, with a maximum of $83 \%$ (for graduates from Ca' Foscari, Venice) and a minimum of $52 \%$ (Università Orientale, Naples).

Individual and household observables. - We add block $X$, composed of two sets of individual controls (model 3). The first refers to predetermined observables. In particular, we include a dummy for male to capture gender differences and one for immigration status. We also control for family background, using information on both parents' type of occupation and education, by age of enrolment and by occupational status during enrolment. Above all, we include the mark awarded at the end of secondary education and the type of secondary education. The second block includes a full set of educational observables describing postgraduate studies and degrees.

The sign of the coefficients of the individual observables, reported in Tables (5) and (6) for second and single-cycle graduates, is consistent with theory and past evidence. The employment probability is higher for males and natives. The father's employment status is positively and significantly correlated with the probability of employment. High school marks are positively correlated with employment. On the other hand, the sign of coefficients relating to

\footnotetext{
${ }^{8}$ For the first estimated model (the one with only university dummies and constant) differences are taken from the unconditional grand mean. Detailed regression results are available for second-cycle and single-cycle graduates (Tables (5) and (6)), together with predictions for employment, earnings and employment-weighted earnings (Tables (7) and (8)). Similar tables for first-cycle graduates are available upon request.

${ }^{9}$ This is made plain, for instance, by the estimates for two universities located in Bari: Bari Politecnico and Bari University. The former is specialized in engineering and architecture and its prediction drops when the FIELD dummies are introduced. The opposite is true for Bari University, which is specialized in most of the remaining fields.
} 
technical and vocational secondary education is positive. This is striking, since in Italy students from these high schools perform worse in standardized tests (OECD, 2014). This can be explained by the fact that only relatively few, highly motivated students enter tertiary education from professional and technical schools, while most of those attending academic high schools go on to university. In addition, graduates of better secondary schools may have taken time to select better job offers after graduation. The remaining educational observables refer to post-graduation educational choices. They show positive coefficients when they are associated with short post-graduate courses (for instance, master courses), negative ones when they refer to long courses (for instance, $\mathrm{PhD}$ ) or to degree courses in progress. One possible reason is that those who earned a long-course post-graduate degree had less time to find a job (not more than a year in the case of holders of a PhD). Similarly, those attending post-graduate courses may put very little effort into searching forwork. Predictions of employment at university level range from $82 \%$ for Bocconi, Milan, to $56 \%$ for Università Orientale, Naples.

Local Labour Markets. - University outcomes are also affected by the local labour market in which the university is located. In model 4, we proxy it with the employment rate of graduates in their region of origin $(P R E)$.

In the final specification (model 5), we control for the local labour market by using the employment rate of the region of current residence $(P O S T)$ : compared with the variable PRE, POST is a better proxy, but it is likely endogenous. This is why we estimate model 5 also by IV (model 5 IV). Figure (2) shows our first ranking (out of three) of universities according to the final employment predictions. Employment probabilities range from $60 \%$ for the University of Cassino to $79 \%$ for Bocconi, Milan. Hence, accounting for factors related to specialization, differences in individual observables and in local labour market conditions reduce the range of employment predictions across universities by $47 \%$ (from 38 percentage point in the basic model to 20 percentage points in model 5 IV).

\subsection{Earnings and employment-weighted earnings}

We supplement the analysis by looking at labour income. Earnings give valuable information on the returns to education, particularly for universities with high employment rates. While no university of course reaches a 100\% employment rate, some do approach it: for second- and single-cycle degrees, there are five universities with employment rates above $90 \%$ (Politecnico di Torino, Politecnico di Milano, Bocconi, University of Bergamo and University of Bolzano), suggesting that graduates from these universities may be near full employment.

Figure (3) shows our second ranking, which is based on earnings predictions: estimates range from 1199 (Università Orientale, Naples) to 1831 (University of Bolzano) in model 5 IV. 
Finally, given that we observe earnings only for individuals who are employed, we calculated a synthetic measure of earning and employment, multiplying each university employment rate by the corresponding average earning. We obtain employment-weighted earnings and use them for our third ranking. Predictions for employment-weighted earnings for each university are reported in Tables (9) and (10)

A graphical illustration of this university ranking is provided in Figure (4). Employmentweighted earnings range from 757 (Università Orientale, Naples) to 1292 (Bocconi, Milan, which ranks first). Accounting for specialization, individual observables and local labour markets explains roughly half $(46 \%)$ of the initial range of employment-weighted earning predictions across universities.

\subsection{Differences across areas}

Figure (5) shows a very clear geographic pattern: raw employment-weighted earnings are noticeably lower in universities located in the South than in other areas: in the basic model, they amount to 840 euros, compared with 1197 euros in those located in the North-West. As the provision of tertiary education is geographically quite balanced in terms of specialization, controlling for it does not significantly affect the predictions once they are aggregated by area. A small reduction in average employment-weighted earnings is observed for universities located in North-West, showing a relative specialization in fields with better labour market returns, the opposite holds for the universities located in the Centre. Adding individual observable characteristics of students to the model slightly reduces the North-South divide, too, indicating that those enrolled in the South are observationally worse on average.

The impact of local labour market variables is greater though qualitatively comparable. Compared with the previous model, the inclusion of the variable PRE impacts positively overall on the universities located in the South and negatively on the others. This pattern is further reinforced when $P R E$ is replaced by POST, as shown in the figure. If current region of residence is endogenous, OLS estimates for the geographical divide may be upward biased. This would result in underestimating the differences between the effects of universities located in different regions. This is exactly what we find when we instrument POST with PRE: geographical differences tend to increase, moving slightly back towards the ones of previous specifications. Nevertheless, the differences in employment-weighted earnings across areas are much smaller on average than in the raw estimates (955 euros in the South and 1110 euros in the North-West), while there is basically no difference in the outcomes for universities located in the Centre and North-East. Hence, accounting for specialization, individual observables and local labour markets reduces the gap between the North-West and the South by $40 \%$. 


\subsection{First cycle and second cycle}

In Figure (6) we compare estimated predicted values for the first cycle with those for secondand single-cycle degree courses, using the final IV regression (model 5 IV). First-cycle and second-cycle employment effects are positively correlated. The same holds for earnings.

As can be expected, the likelihood of employment is higher for second- and single-cycle graduates: the difference is about 6 percentage points. Some universities perform better in the first cycle than in the following one: all but one are located in the North (Figure (6), panel (a)). On average, this implies that employment increases more in the Centre and South across cycles.

The conclusion is reversed as far as earnings are concerned (Figure (6), panel b): predictions for universities located in the North-West and North-East for second-cycle graduates are respectively 104 and 140 euros higher than for first-cycle graduates, as against a difference of only 34 euros in the South and a negative difference in the Centre. Hence, on average, earnings increase less across cycles for graduates of universities located in the Centre and South than in the North.

Given first-cycle estimated effects, for second-cycle graduates universities located in the South tend to do better in terms of employment but worse in terms of earnings than universities in the North. A graphical intuition is given in Figure (7): while for first-cycle degrees (panel a), universities in the South are dominated in terms of employment (the blue points are mostly on the right), for second-cycle degrees (panel b) the dominance is mostly due to earnings differentials with respect to the rest of the country (i.e. the blue points are mostly above).

\subsection{Comparison with other university rankings}

Table (11) reports the groups of indicators included in some of the best-known Italian and international university rankings. ${ }^{10}$ We compare them with our final ranking (model 5 IV), based on employment-weighted earnings, and with the raw employment-weighted earnings (deriving from model 1).

The Thompson Reuters-Times Higher Education 2011 (THE 2011) World University Ranking (Thomson Reuters-Times, 2011) is based on a list of performance indicators, grouped into five areas: teaching; research; citations (research influence); industry income (innovation); international outlook of staff, students and research. The Quacquarelli and Symonds 2011 (QS 2011) ranking (QS, 2011) considers indicators for the above-mentioned areas plus additional ones that refer to the facilities and infrastructures available to students, the university's engagement in the development of its local community, and its accessibility to students (disability access, scholarships, gender balance, etc.). Most importantly, a third ranking,

\footnotetext{
${ }^{10}$ As graduates in our sample were interviewed in 2011, we report the 2011 rankings whenever possible.
} 
the 2011 Academic Ranking of World Universities (ARWU 2011) (ARWU, 2011) includes a measure of employability, defined as the ability to work effectively as part of a team, deliver presentations, and manage people and projects. Indicators for employability are derived from surveys of employers, graduates' employment rates and average salaries. THE 2011, QS 2011 and ARWU 2011 include only a very small sub-sample of Italian universities (less than one third at best). This probably explain the absence of significant co-graduation our rankings with any of them (Table 12).

The Webometrics 2013 (Webometrics, 2013) ranking includes all the universities we have in our sample of graduates. It is elaborated on data available on the web and by means of a link analysis. The final indicator derives from the composition of four objects, measuring university visibility (by the number of external links that the university web-domain receives from third parties), presence (by the number of pages hosted in the main web-domain of the university and indexed by Google), openness (by the number of pdf, doc, docx and ppt files published indexed by Google Scholar), excellence (by the number of scholarly papers among the $10 \%$ most frequently cited in their respective fields). The basic ranking (model 1) obtained in this paper correlates positively and significantly with the Webometrics 2013 ranking, but co-graduation and significance disappear when we come to our final ranking (model $5 \mathrm{IV}$ ).

We also consider three national rankings. In Table (12) we report Spearman's rank correlation of our employment-weighted earnings ranking with a measure of quality obtained obtained from data from Italy's National Agency for the Evaluation of Universities and Research Institutes (ANVUR, 2013). The indicator calculated by ANVUR is mainly a measure of research quality. ${ }^{11}$ We find evidence of a positive and significant co-graduation, but not very strong (Spearman's rho is 0.43 for the raw estimates and 0.28 for model 5 IV ranking). This supports the idea that the two evaluations (one on research, the other on employability) are complementary, as they assess two different outcomes, although both are correlated with the quality of the university. Secondly, the correlation is stronger and more statistically significant for the basic ranking.

Censis, together with the newspaper La Repubblica, annually publishes a league table using indicators on productivity, research, teaching and international relations (see CensisLa Repubblica (2011) for details). The ranking calculated by the newspaper Il Sole 24 Ore uses similar information (albeit measured, in most cases, by different indicators). That

\footnotetext{
${ }^{11}$ For each university, we have obtained an indicator of quality starting from the indicator IRFS1 (Indicatore finale di struttura) calculated by ANVUR (2013). It reflects research quality (weight=0.5), staff mobility, ability to attract external funding, internationalization, own endowments, quality of postgraduates courses, and improvement (weight $=0.1$ for each indicator). Data were collected from Table 6.10a in ANVUR (2013). For details on the construction of IRFS1, see ANVUR (2013). IRFS1 has been normalized by the share of expected research products of each university (a quantity proportional to the number of research units in each university, also calculated by ANVUR) to obtain a measure of quality which does not reflect the size of the staff.
} 
ranking also includes a measure of employment (i.e. the employment rate of students three years after graduation). Both rankings are significantly co-graduated with the raw estimates in this paper; that of Il Sole 24 Ore is also co-graduated with our final employment-weighted earnings ranking. In all cases, as in the ANVUR ranking, the co-graduation decreases as we go from the raw to the final ranking, indicating that the league tables used as terms of comparison may also capture, together with university quality, additional context factors.

\section{Main limitations}

In this section we discuss possible limitations of our results. Whenever feasible we propose alternative estimation procedures to assess their robustness.

In order to obtain consistent estimates of the parameters of interest $\beta_{U N}$ from model (2.1) we have implicitly assumed that graduates self-select into different universities according to observable characteristics (selection on observables, see Rosenbaum and Rubin, 1983, and Black and Smith, 2004). Violations of this assumption can result in an ability bias. If better students self-select in better universities, the estimated university effects associated with the latter (former) can be expected to be upward (downward) biased. This would tend to increase the variability of university fixed effects and predicted values. The assumption of selection on observables at the entry of university may be violated for a series of reasons. First, the resident population may have unobserved ability differentials. The existence of this heterogeneity is corroborated to some extent by the large number of studies reporting pronounced geographical differences in students' achievements in primary and secondary education (see, for instance, Braga and Checchi, 2010). Selection can also result as a consequence of restrictive admission policies, which in Italy are mainly limited to certain fields (medicine above all, see Sestito and Tonello, 2012, for details) and universities (chiefly private institutions). Also mobility may matter, perhaps less than expected: Brunello and Cappellari (2008) show that mobility to universities in other geographical areas does not concentrate on students with a better family backgrounds. A possible solution to the violation would be to instrument all the university dummies. We tried using the full set of dummies for the province of residence before university and, as an alternative, building for each individual and for each university a variable indicating the fraction of individuals from his/her province of origin who attended that university in the previous years. There are two problems with these strategies. First, the choice of a university is not always strongly related to the instruments. This creates a weak instrument problem that contaminates the whole estimation, generating several predictions that are outside the boundaries $[0,1]$ and highly imprecise. Second, this strategy makes it necessary to instrument a very long set of binary variables, which is not common practice in the literature. Other instruments using geographical variation, such as the local cost of living or measures of distance, cannot be employed in this context because of collinearity. 
The reason is that some universities have the same geographical position because they are located in the same town or province.

In order to reduce the possible sorting bias we have included a large set of pre-determined variables. As we control for pre-enrolment study outcomes (type of secondary school degree and school-leaving mark), our model can be interpreted as a basic version of a value added model (McGuinness, 2003 and Ricci, 2008). But, as pre-determined variables are also likely to capture most of the difference in unobserved ability between graduates from different universities, our estimates are also partially clearing the estimated fixed effects for the ability of each university to attract better students.

A bias may also result from the inclusion of variables related to post-graduate studies, which are likely endogenous. Even assuming that selection on observables upon university entry holds, the sign of the bias is unclear. It depends both on the correlation between postgraduate studies and unobserved graduates' ability, and on the association between university quality and the likelihood of pursuing further education. Alternatively, we could drop the observations of graduates who have been engaged or are engaged in post-graduation activities at the time of the interview. However, if this is not somehow taken into account, we would penalize universities where graduates have a higher propensity to engage in further studies, which does not seem to be a bad signal per se. The impact of post-graduation educational observables is quite small: the correlation coefficient of university fixed effects from model 3 with those from a similar model without post-graduation educational observables is 0.98 and statistically highly significant (Figure 8, panel a). ${ }^{12}$ The impact of these variables on most universities is negligible. Exceptions are the universities whose graduates are largely involved in post-graduate education (among them, some universities specialized in medicine)

Other problems derive from dropout rates and selection across subjects of study. Concerning the first point, we have decided not to clear for differences in the dropout rate across universities. Including it would imply considering an additional endogeneity issue. Concerning the second point, if more talented students self-select into fields of studies that offer better employment prospects, then the related dummies are likely to be upward biased. As a consequence, the effect for universities specialized in these subjects is possibly underestimated. The opposite is true for field of studies associated with worse employability. This is a limitation of the present study, but, as with the problem of self-selection into universities, we do not have a solution. Instead of university fixed effects, we could estimate a set of interactions between universities and subjects. Although this would not solve the problem of self-selection into fields of studies, it would allow us to compare alma mater effects within each subject. Nevertheless, we elect to avoid this alternative because it leads to a substantial increase in the number of coefficients of interest and to a reduction in the precision of the

\footnotetext{
${ }^{12}$ We perform this analysis on the sample of second- and single-cycle graduates, where we expect the issue to be more relevant.
} 
estimates.

To solve the endogeneity in the choice of the current region of work, we proposed an IV estimation, where employment in that region is instrumented by the same variable measured in the region of origin. The IV estimation recovers consistent estimates of the university fixed effects as long as we assume that the observable characteristics in $X$ and FIELD are enough to remove any correlation between $P R E$ and individual unobservable heterogeneity, so that origin is a valid instrument for current region. If this is not the case, the OLS regression of $y$ on $U N, P O S T$, FIELD and $X$ would estimate a $\beta_{U N}$ which is a mix of university, selection and geographic effects, while the IV strategy would be of no help.

To account for local labour market we used the regional employment rate of graduates, which is clearly not available for graduates from abroad and for those who moved abroad after graduation. Consequently, we dropped these observations. An alternative is to keep them and to estimate the model using the regional employment rates - set to the mean for graduates from and moving abroad - and an additional dummy for those graduates. Results from this model are compared with estimates from model 5 IV in Figure 8, panel b, showing no major difference for almost all universities.

One possible alternative would have been to employ regional dummies. This would have required instrumenting each dummy for current region of residence with dummies for the one where the individual resided before university. This solution leads to quite imprecise estimates, especially for some of the smaller regions. Indeed, the Kleibergen-Paap Wald rk F statistic indicates a problem of weak instruments, because it is quite small in all specifications, ranging from 2.2 in the estimates for employment in the first-cycle degree, to 12.0 in the wages regression for the second- and single-cycle degrees. An alternative would be to employ dummies at a more aggregate level, such as North-West, North-East, Centre and South. Our choice, which uses graduates' employment rate as a proxy for the quality of the local labour market, is a trade-off between precision of estimates and the need to consider geographical variability at a finer level.

In general, we impose linearity throughout the paper. The reason is that our final specification is estimated using IV, for which we prefer to use the standard 2SLS estimator. However, this might be seen as particularly restrictive given the focus on binary outcomes when dealing with employment. For completeness, we also compare estimates from a probit specification. Overall, probit predictions are quite similar to the OLS ones (Figure 8, panel c). The mean absolute difference across the full OLS and the probit predictions is 0.79 percentage points. Differences across specification are mostly concentrated on the predictions of universities that displayed very high (or very low) raw employment rates. For instance, for the University of Bolzano, whose raw employment rate was 90\%, the probit specification predicts an employment rate 3 percentage points lower with respect to OLS.

Some caveats are specific to the earnings equation. Exploiting information on labour 
income from the IIPL is not immediate, because the information is missing for roughly one fifth of the employed units. and this, moreover, is very unlikely to be random. In fact, even assuming that it is random in the sample, it would not be random across universities, because missing labour income is only observed for employed graduates and employment rates are different across universities. To check for consistency, we have also estimated model 5 IV for employment using only units with non-missing earnings. When the model is estimated on this sub-sample, average employment falls by roughly 5 per cent (Figure 8, panel d), as dropped units refer to employed individuals. Missing units are relatively more numerous for universities in the South; as they are attributable to employed workers who are worse than the average according to most observables, their presence is likely due to upward bias fixed effects for universities in the South. In Figure (9) we show a version of the final employment-weighted earnings ranking where employment has been estimated only on units with non-missing earnings.

The earnings equation has been assumed as log-linear in the main specification. For this reason, in calculating the predictions we also employed the correction method suggest by Wooldridge (2006). It implies rescaling all the predictions $\hat{y}=\exp (x b)$ by a factor obtained by regressing original values y on $\hat{y}$ without a constant. Given that we calculated average marginal effects (AME) across the exponentiated predictions, this correction does not guarantee that the grand mean for AME is equal to the sample mean for y. Nevertheless, the difference is quite small. This problem would not be posed if we calculated AME from a non-linear estimation of an exponential model. We did this by using Windmeijer and Santos Silva (1997) Poisson-GMM. Predicted earnings are quite similar, as can be observed in Figure (8), panel (e).

We have also assumed that employment and wages are independent and so we did not use an Heckman selection model. ${ }^{13}$ This would have implied dealing with two sources of endogeneity at the same time: one coming from selection into local labour market, the other from selection into employment. While we have proposed an instrument for the former, we do not have a clear source of exogenous variability for the latter, and we prefer not to rely on function form restrictions only.

\section{Conclusion}

In this paper we studied a method for the evaluation of university quality. Rather than focusing on the quality of research or on services provided by the universities, our evaluation is based on graduates' labour outcomes. Although different kinds of employment indicators have already been used in some league tables or in the allocation of resources in some countries,

\footnotetext{
${ }^{13}$ The same assumption is maintained for first- versus second- cycles graduates.
} 
in this paper we examined how to account for geographical disparities in greater suggest and suggested a method that can counteract the potential bias induced by selection in local labour markets.

An important result is that by accounting for specialization, graduates' observable characteristics and for their current local labour markets, we explain a significant part of the differentials in labour market outcomes of Italian universities. In particular, in terms of employment-weighted earnings, the gap between universities based in the North-West and those in the South is reduced by $40 \%$. This suggests that simple rankings based on the unconditional employment rate are not likely to reflect the true contribution of each university to the employability of their graduates, but also highlights a limitation of other outcome measures, which may reflect the contribution of external factors to quality.

We pointed out the main problems that arise in attempting to correct for other sources of heterogeneity. For instance, our IV estimates show that simply accounting for the regional employment rate can lead to underestimating the true differentials between universities located in different areas. As discussed in Section 5, other sources of bias may affect our estimates.

Furthermore, our reasonably simple econometric model may be considered too simple to be sufficiently accurate but also too complicated to be actually implemented in evaluation practice. Nevertheless, with respect to league table indicators, our formal structure has the advantage of having clear assumptions that can be explicitly discussed. We therefore believe that our analysis can be used for critical assessment of simpler rankings that can be produced using data on graduates' employment and earnings.

Finally, this type of evaluation would benefit significantly from the availability of repeated and comparable cross sections, in order to assess not only universities' quality but also their improvement over time. The precision of the estimated coefficients would also stand to gain from this. Greater availability of micro-data is undoubtedly necessary in order to make effective use of labour market information for the evaluation of universities. 


\section{References}

ANVUR (2013), Valutazione della qualità della ricerca 2004-2010, Rapporto finale.

ARWU (2014), http://www.shanghairanking.com/aboutarwu.html.

Braga, M., and D. Checchi (2010), "Sistemi scolastici regionali e capacità di sviluppo delle competenze. I divari dalle indagini Pirls e Pisa", Italian Journal of Social Policy, 3.

Black, D. A., and J.A. Smith (2004), "How Robust is the Evidence on the Effects of College Quality? Evidence from Matching", Journal of Econometrics, vol. 121.

Brunello, G., and L. Cappellari (2008), "The labour market effects of Alma Mater: Evidence from Italy", Economics of Education Review, 27(5).

Censis-La Repubblica (2011), "Nota metodologica", Grande Guida dell'Università 2011-2012.

Cipollone, A., P. Montanaro and P. Sestito (2010)," Misure di valore aggiunto per le scuole superiori italiane: i problemi esistenti e alcune prime evidenze", Banca d'Italia Working Paper No. 754.

Coe, R., and C.T. Fitz-Gibbon (1998), "School Effectiveness Research: Criticisms and Recommendations", Oxford Review of Education, 24 (4).

De Simone, G., B. Monastero and A. Stanchi (2009), "Un esercizio di valutazione esterna: come le Università piemontesi giudicano (indirettamente) le scuole della Regione", Fondazione Giovanni Agnelli Working Paper No. 18/09.

Fondazione Agnelli (2013), La valutazione della scuola. A cosa serve e perchè è necessaria all'Italia, Editori Laterza.

Hanushek, E. A. (2003), "The Failure of Input-Based Schooling Policies", The Economic Journal, 113.

McGuinness, S. (2003), "University Quality and Labour Market Outcomes", Applied Economics, 35. 
OECD (2014), PISA 2012 Results: What Students Know and Can Do: Student Performance in Mathematics, Reading and Science, Paris.

QS (2011), http://www.topuniversities.com/qs-stars/qs-stars-methodology.

Ricci, R. (2008, 2012), "La misurazione del valore aggiunto nella scuola", FGA Working Paper 9.

Robst, J. (1995), "Career Mobility, Job Match, and Overeducation", Eastern Economic Journal, Eastern Economic Association, 21(4).

Rosenbaum, P. R., and D.B. Rubin (1983), "The central role of the propensity score in observational studies for causal effects", Biometrika, 70(1).

Sestito, P., and M. Tonello (2012), "I differenziali nella qualità degli iscritti alle università italiane: il caso delle facoltà di medicina e chirurgia", Banca d'Italia Occasional Paper No.90.

Sole 24 Ore, http://opendatablog.ilsole24ore.com/2011/07/le-migliori-universita-italiane

Thomson Reuters-Times (2011), The Times Higher Education World University Ranking, http:// www.timeshighereducation.co.uk/world-university-rankings/2011-12/world-ranking/methodology

Webometrics (2014), http://www.webometrics.info/en/Methodology

Windmeijer, F., and J. M. C. Santos Silva (1997)," Endogeneity in count data models: An application to demand for health care", Journal of Applied Econometrics 12: 281-294

Wooldridge, J. (2006), Introductory Econometrics: A Modern Approach, International Edition, Thomson 


\section{Tables and Figures}

Table 1: Sample selection

\begin{tabular}{lcccc}
\hline Step & First-cycle degree & \multicolumn{2}{c}{$\begin{array}{c}\text { Second and } \\
\text { single-cycle degree }\end{array}$} \\
\hline & Obs & \% change & Obs & $\%$ change \\
\hline $\begin{array}{l}\text { 1. Original sample } \\
\text { 2. Dropping missing in X }\end{array}$ & 30,912 & & 31,088 & $-1.6 \%$ \\
$\begin{array}{l}\text { 3. Dropping students from abroad or } \\
\text { graduates who moved abroad }\end{array}$ & 30,591 & $-1.0 \%$ & 30,597 & $-3.4 \%$ \\
$\begin{array}{l}\text { 4. Dropping small universities and } \\
\text { distance-learning ones }\end{array}$ & 29,362 & $-4.0 \%$ & 29,566 & $-4.2 \%$ \\
\hline
\end{tabular}


Table 2: Sample average of individual characteristics

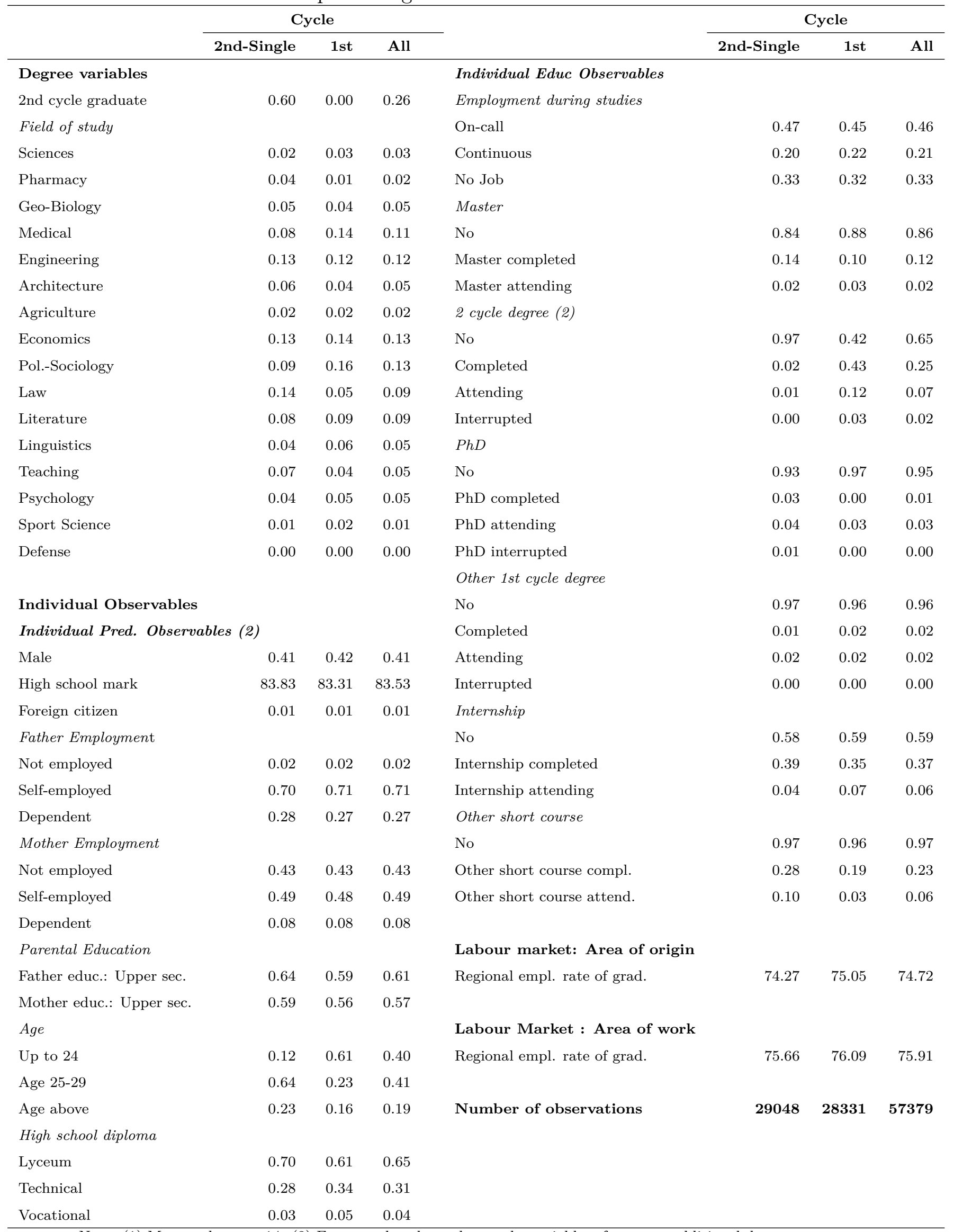

Note: (1) Measured at age 14. (2) For second cycle graduates the variable refers to an additional degree. 
Table 3: Mobility from area of origin to area of the university

(a) First-cycle degree

\begin{tabular}{lccccc}
\hline \multirow{2}{*}{$\begin{array}{l}\text { Area of residence } \\
\text { before university }\end{array}$} & NW & NE & CE & SO & Total \\
\cline { 2 - 5 } NW & 0.91 & 0.05 & 0.03 & 0.01 & 1 \\
NE & 0.06 & 0.89 & 0.03 & 0.02 & 1 \\
CE & 0.03 & 0.03 & 0.90 & 0.04 & 1 \\
SO & 0.05 & 0.04 & 0.14 & 0.77 & 1 \\
\hline Total & 0.25 & 0.20 & 0.25 & 0.31 & 1 \\
\hline
\end{tabular}

(b) Second and single-cycle degree

\begin{tabular}{lccccc}
\hline \multirow{2}{*}{$\begin{array}{l}\text { Area of residence } \\
\text { before university }\end{array}$} & NW & NE & CE & SO & Total \\
\cline { 2 - 6 } NW & 0.91 & 0.06 & 0.02 & 0.01 & 1 \\
NE & 0.06 & 0.90 & 0.03 & 0.01 & 1 \\
CE & 0.02 & 0.04 & 0.91 & 0.03 & 1 \\
SO & 0.05 & 0.05 & 0.13 & 0.77 & 1 \\
\hline Total & 0.23 & 0.18 & 0.25 & 0.35 & 1 \\
\hline \multicolumn{5}{r}{ Source: IIPL 2007, Istat }
\end{tabular}

Table 4: Mobility from area of the university to the current area of residence

(a) First-cycle degree

\begin{tabular}{lccccc}
\hline \multirow{2}{*}{$\begin{array}{l}\text { Area of the } \\
\text { university }\end{array}$} & \multicolumn{5}{c}{ Area of residence after university } \\
\cline { 2 - 6 } NW & NE & CE & SO & Total \\
\hline NE & 0.90 & 0.04 & 0.03 & 0.03 & 1 \\
CE & 0.08 & 0.85 & 0.04 & 0.03 & 1 \\
SO & 0.05 & 0.03 & 0.79 & 0.12 & 1 \\
\hline Total & 0.07 & 0.05 & 0.08 & 0.81 & 1 \\
\hline
\end{tabular}

(b) Second and single-cycle degree

\begin{tabular}{lccccc}
\hline \multirow{2}{*}{$\begin{array}{l}\text { Area of the } \\
\text { university }\end{array}$} & NW & NE & CE & SO & Total \\
\cline { 2 - 6 } NW & 0.90 & 0.04 & 0.03 & 0.03 & 1 \\
NE & 0.10 & 0.81 & 0.05 & 0.05 & 1 \\
CE & 0.06 & 0.04 & 0.80 & 0.10 & 1 \\
SO & 0.08 & 0.03 & 0.08 & 0.81 & 1 \\
\hline Total & 0.26 & 0.17 & 0.24 & 0.32 & 1 \\
\hline \multicolumn{5}{c}{ Source: IIPL 2007, Istat }
\end{tabular}


Table 5: Main models for employment (second and single-cycle): 1/2

\begin{tabular}{|c|c|c|c|c|c|c|c|c|c|c|}
\hline \multirow{4}{*}{ Degree Variable } & \multicolumn{2}{|c|}{ model (2) } & \multicolumn{2}{|c|}{ model (3) } & \multicolumn{2}{|c|}{ model (4) } & \multicolumn{2}{|c|}{ model (5) } & \multicolumn{2}{|c|}{ model (5) IV } \\
\hline & \multicolumn{2}{|c|}{ Field of study } & \multicolumn{2}{|c|}{ Ind. Obs } & \multicolumn{2}{|c|}{ Area of origin } & \multicolumn{2}{|c|}{ Lab market - OLS } & \multicolumn{2}{|c|}{ Lab market - IV } \\
\hline & \multicolumn{2}{|c|}{ FIELD } & \multicolumn{2}{|c|}{$\mathrm{X}$} & \multicolumn{2}{|r|}{ PRE } & \multicolumn{2}{|c|}{ POST OLS } & \multicolumn{2}{|c|}{ POST IV } \\
\hline & & & & & & & & & & \\
\hline Degree Duration & -.0717 & $(.0073)$ & -.0897 & $(.0073)$ & -.0896 & $(.0073)$ & -.0899 & $(.0072)$ & -.0898 & $(.0072)$ \\
\hline \multicolumn{11}{|c|}{ Field of study (ref:Scien) } \\
\hline Pharmacy & .121 & $(.0201)$ & .126 & $(.0175)$ & .126 & $(.0175)$ & .137 & $(.0175)$ & .133 & $(.0175)$ \\
\hline Geo-Biology & -.175 & $(.0239)$ & -.114 & $(.0205)$ & -.113 & $(.0205)$ & -.107 & $(.0203)$ & -.11 & $(.0204)$ \\
\hline Medical & -.309 & $(.0165)$ & -.236 & $(.0168)$ & -.236 & $(.0168)$ & -.229 & $(.0166)$ & -.232 & $(.0167)$ \\
\hline Engineering & .148 & $(.0163)$ & .0861 & $(.014)$ & .0858 & $(.014)$ & .086 & $(.0139)$ & .086 & $(.0138)$ \\
\hline Architecture & .0889 & $(.0193)$ & .0444 & $(.0173)$ & .0446 & $(.0173)$ & .051 & $(.0173)$ & .0487 & $(.0172)$ \\
\hline Agriculture & .0137 & $(.0253)$ & .0109 & $(.0228)$ & .0107 & $(.0227)$ & .0204 & $(.023)$ & .017 & $(.0229)$ \\
\hline Economics & .0668 & $(.0166)$ & -.0088 & $(.0145)$ & -.0085 & $(.0145)$ & -.0024 & $(.0144)$ & -.0047 & $(.0144)$ \\
\hline Pol.-Soc. sc. & .0437 & $(.0184)$ & -.0434 & $(.0164)$ & -.0423 & $(.0164)$ & -.0329 & $(.0162)$ & -.0366 & $(.0164)$ \\
\hline Law & -.0945 & $(.0189)$ & -.133 & $(.0172)$ & -.132 & $(.0172)$ & -.119 & $(.0171)$ & -.124 & $(.0173)$ \\
\hline Literature. & -.0641 & $(.0232)$ & -.103 & $(.0209)$ & -.103 & $(.0209)$ & -.0975 & $(.0207)$ & -.0995 & $(.0208)$ \\
\hline For. Lang & .0011 & $(.0237)$ & -.0577 & $(.0221)$ & -.0574 & $(.0221)$ & -.0525 & $(.0219)$ & -.0544 & $(.0219)$ \\
\hline Teaching & .16 & $(.0194)$ & .0927 & $(.0186)$ & .0922 & $(.0186)$ & .0921 & $(.0183)$ & .0923 & $(.0183)$ \\
\hline Psycology & -.025 & $(.0292)$ & .0266 & $(.0297)$ & .0284 & $(.0298)$ & .0385 & $(.0293)$ & .0342 & $(.0295)$ \\
\hline Sport science & .0491 & $(.0226)$ & -.0537 & $(.0213)$ & -.0519 & $(.0213)$ & -.0461 & $(.0211)$ & -.0488 & $(.0212)$ \\
\hline Defense & .147 & $(.0247)$ & .0054 & $(.0234)$ & .0207 & $(.0244)$ & .0611 & $(.0242)$ & .0412 & $(.027)$ \\
\hline$F$ (p-value) & 228.85 & $(.0000)$ & 71.98 & $(.0000)$ & 71.62 & $(.0000)$ & 71.07 & $(.0000)$ & 71.23 & $(.0000)$ \\
\hline \multicolumn{11}{|c|}{ Individual Pred. Observables (1) } \\
\hline Male & & & .0497 & $(.0065)$ & .05 & $(.0065)$ & .0496 & $(.0064)$ & .0497 & $(.0064)$ \\
\hline High school mark & & & $6.4 \mathrm{e}-04$ & $(3.0 \mathrm{e}-04)$ & $7.1 \mathrm{e}-04$ & $(3.0 \mathrm{e}-04)$ & $6.1 \mathrm{e}-04$ & $(2.9 \mathrm{e}-04)$ & $6.2 \mathrm{e}-04$ & $(2.9 \mathrm{e}-04)$ \\
\hline Foreign citizen & & & -.126 & $(.0616)$ & -.128 & $(.0617)$ & -.126 & $(.0621)$ & -.126 & $(.0618)$ \\
\hline Self employed (Fa & & & .0353 & $(.0268)$ & .0339 & $(.0267)$ & .03 & $(.026)$ & .0319 & $(.0262)$ \\
\hline Dependent (Fath. & & & .0502 & $(.0272)$ & .0486 & $(.027)$ & .0455 & $(.0263)$ & .0472 & $(.0265)$ \\
\hline Self employed (Mc & th.) & & -.004 & $(.0073)$ & -.0047 & $(.0073)$ & -.0053 & $(.0072)$ & -.0048 & $(.0072)$ \\
\hline Dependent (Moth & & & -.0062 & $(.0119)$ & -.0073 & $(.0119)$ & -.0091 & $(.0118)$ & -.0081 & $(.0118)$ \\
\hline Upper sec educ. & ath.) & & .0097 & $(.0084)$ & .0097 & $(.0084)$ & .0092 & $(.0083)$ & .0094 & $(.0083)$ \\
\hline Upper sec educ. ( & Moth.) & & .0137 & $(.0085)$ & .0142 & $(.0085)$ & .0142 & $(.0085)$ & .014 & $(.0085)$ \\
\hline Age $25-29$ & & & -.0244 & $(.0091)$ & -.0242 & $(.0091)$ & -.0248 & $(.009)$ & -.0246 & $(.009)$ \\
\hline Age above & & & -.0183 & $(.0126)$ & -.0174 & $(.0126)$ & -.0138 & $(.0125)$ & -.0154 & $(.0126)$ \\
\hline Technical diploma & & & .0026 & $(.0078)$ & .0022 & $(.0078)$ & .0031 & $(.0077)$ & .0029 & $(.0077)$ \\
\hline Vocational diplom & & & .0215 & $(.0164)$ & .0208 & $(.0164)$ & .0255 & $(.0162)$ & .0241 & $(.0162)$ \\
\hline$F(p$-value $)$ & & & 39.06 & $(.0000)$ & .113 & $-.0901(.008)$ & 39.48 & $(.0000)$ & 39.58 & $(.0000)$ \\
\hline
\end{tabular}

Note: SE in brackets. The F statistic refers to the the joint test for the significance of the block of variables under the same heading in bold (p-value in brackets) - (1) Measured at age 14; Source: IIPL 2007, Istat 
Table 6: Main models for employment (second and single-cycle): 2/2

\begin{tabular}{|c|c|c|c|c|c|c|c|c|c|}
\hline \multirow{2}{*}{\multicolumn{2}{|c|}{$\begin{array}{c}\text { model (2) } \\
\text { FIELD }\end{array}$}} & \multirow{2}{*}{\multicolumn{2}{|c|}{$\begin{array}{c}\text { model (3) } \\
\mathrm{X}\end{array}$}} & \multirow{2}{*}{\multicolumn{2}{|c|}{$\begin{array}{l}\text { model (4) } \\
\text { PRE }\end{array}$}} & \multirow{2}{*}{\multicolumn{2}{|c|}{$\begin{array}{l}\text { model (5) } \\
\text { POST OLS }\end{array}$}} & \multirow{2}{*}{\multicolumn{2}{|c|}{$\begin{array}{l}\text { model (5) IV } \\
\text { POST IV }\end{array}$}} \\
\hline & & & & & & & & & \\
\hline \multicolumn{10}{|c|}{ Individual Educ. Observables } \\
\hline \multicolumn{2}{|c|}{ Continuous job during studies } & .113 & $(.0086)$ & .113 & $(.0086)$ & .113 & $(.0085)$ & .113 & $(.0085)$ \\
\hline \multicolumn{2}{|c|}{ No job during studies } & -.0907 & $(.008)$ & -.0901 & $(.008)$ & -.0882 & $(.008)$ & -.0891 & $(.008)$ \\
\hline \multicolumn{2}{|c|}{ Master completed } & .0319 & $(.0103)$ & .0335 & $(.0103)$ & .0308 & $(.0102)$ & .0312 & $(.0102)$ \\
\hline \multicolumn{2}{|c|}{ Master attending } & -.04 & $(.0263)$ & -.0394 & $(.0263)$ & -.04 & $(.026)$ & -.04 & $(.026)$ \\
\hline \multicolumn{2}{|c|}{ Other 2nd cycle degree completed } & .0047 & $(.0221)$ & .005 & $(.022)$ & .004 & $(.0217)$ & .0043 & $(.0218)$ \\
\hline \multicolumn{2}{|c|}{ Other 2nd cycle degree attending } & -.0586 & $(.0465)$ & -.0584 & $(.0466)$ & -.0528 & $(.0472)$ & -.0549 & $(.0468)$ \\
\hline \multicolumn{2}{|c|}{ Other 2nd cycle degree interrupted } & .0491 & $(.0637)$ & .0516 & $(.0636)$ & .0417 & $(.0639)$ & .0443 & $(.0636)$ \\
\hline \multicolumn{2}{|l|}{ PhD completed } & -.213 & $(.0191)$ & -.212 & $(.0191)$ & -.21 & $(.0189)$ & -.211 & $(.0189)$ \\
\hline \multicolumn{2}{|l|}{$\mathrm{PhD}$ attending } & -.446 & $(.0201)$ & -.447 & $(.0201)$ & -.445 & $(.02)$ & -.445 & $(.02)$ \\
\hline \multicolumn{2}{|c|}{ PhD interrupted } & -.0423 & $(.041)$ & -.0415 & $(.0412)$ & -.0367 & $(.0411)$ & -.0387 & $(.041)$ \\
\hline \multicolumn{2}{|c|}{ Other first-cycle degree completed } & -.0421 & $(.0318)$ & -.0434 & $(.0318)$ & -.0443 & $(.0314)$ & -.0435 & $(.0314)$ \\
\hline \multicolumn{2}{|c|}{ Other first-cycle degree attending } & -.0748 & $(.0334)$ & -.0751 & $(.0335)$ & -.0749 & $(.0326)$ & -.0749 & $(.0328)$ \\
\hline \multicolumn{2}{|c|}{ Other first-cycle degree interrupted } & .0647 & $(.0346)$ & .0635 & $(.0344)$ & .0668 & $(.0348)$ & .0661 & $(.0346)$ \\
\hline \multicolumn{2}{|c|}{ Internship completed } & -.0166 & $(.0072)$ & -.0159 & $(.0072)$ & -.0143 & $(.0072)$ & -.0151 & $(.0072)$ \\
\hline \multicolumn{2}{|c|}{ Internship attending } & -.273 & $(.019)$ & -.272 & $(.0191)$ & -.27 & $(.019)$ & -.271 & $(.019)$ \\
\hline \multicolumn{2}{|c|}{ Other short course completed } & .0193 & $(.0076)$ & .0194 & $(.0076)$ & .0199 & $(.0076)$ & .0197 & $(.0076)$ \\
\hline \multicolumn{2}{|c|}{ Other short course attending } & -.181 & $(.0156)$ & -.181 & $(.0156)$ & -.179 & $(.0154)$ & -.18 & $(.0154)$ \\
\hline \multicolumn{2}{|l|}{$F$ (p-value) } & 73.01 & $(.0000)$ & 73.02 & $(.0000)$ & 72.27 & $(.0000)$ & 72.84 & $(.0000)$ \\
\hline \multicolumn{4}{|c|}{ Regional Employment Rate (region of origin, PRE) (1) } & .0026 & $(9.4 \mathrm{e}-4)$ & & & & \\
\hline \multicolumn{4}{|c|}{ Regional Employment Rate (region of work, POST) } & & & .0119 & $(9.2 \mathrm{e}-4)$ & .0077 & $(.0027)$ \\
\hline \multicolumn{4}{|c|}{$F$ (p-value) for employment rate (PRE model 4; POST model 5) } & 7.88 & $(.0050)$ & 168.51 & $(.0000)$ & 8.27 & $(.0040)$ \\
\hline Constant & $(.051)$ & .684 & $(.0631)$ & 0.50 & $(.0911)$ & -.151 & $(.0896)$ & .148 & $(.197)$ \\
\hline Observations & 29048 & 29048 & & 29048 & & 29048 & & 29048 & \\
\hline \multicolumn{4}{|c|}{ First-stage $F$ statistic } & & & & & 776.21 & \\
\hline R-squared & 0.131 & 0.245 & & 0.255 & & 0.254 & & 0.253 & \\
\hline
\end{tabular}

Note: SE in brackets. The F statistic refers to the the joint test for the significance of the block of variables under the same heading in bold (p-value in brackets) - (1) Region where the graduate was living before enrolment. Source: IIPL 2007, Istat. 
Table 7: Employment and earnings (second and single-cycle): 1/2

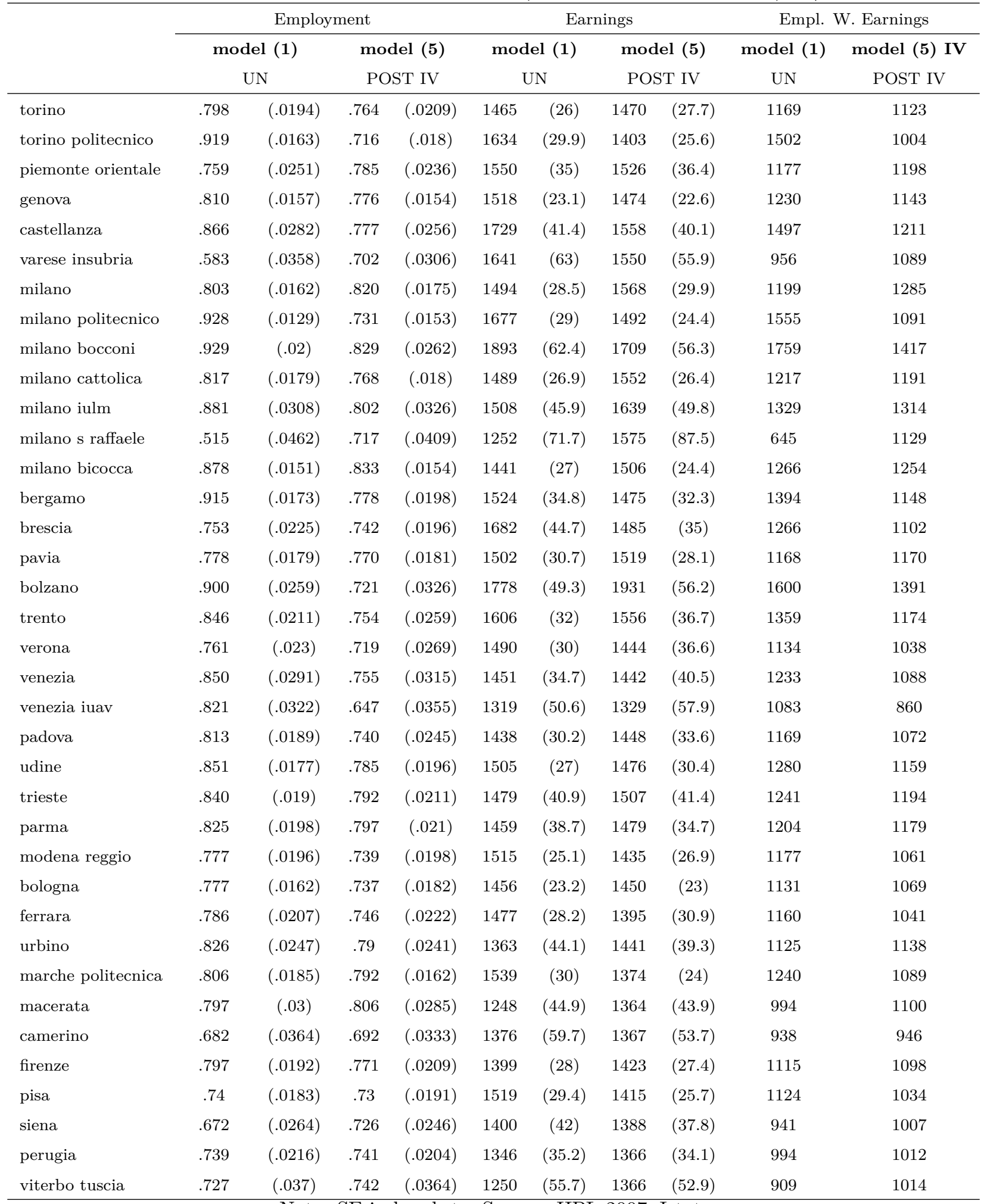

Note: SE in brackets. Source: IIPL 2007, Istat. 
Table 8: Employment and earnings (second and single-cycle): 2/2

\begin{tabular}{|c|c|c|c|c|c|c|c|c|c|c|}
\hline \multirow[b]{4}{*}{ roma sapienza } & \multicolumn{4}{|c|}{ Employment } & \multicolumn{4}{|c|}{ Earnings } & \multicolumn{2}{|c|}{ Empl. W. Earnings } \\
\hline & \multirow{2}{*}{\multicolumn{2}{|c|}{$\begin{array}{c}\text { model (1) } \\
\text { UN }\end{array}$}} & \multirow{2}{*}{\multicolumn{2}{|c|}{$\begin{array}{c}\text { model (5) } \\
\text { POST IV }\end{array}$}} & \multirow{2}{*}{\multicolumn{2}{|c|}{$\begin{array}{c}\text { model (1) } \\
\text { UN }\end{array}$}} & \multirow{2}{*}{\multicolumn{2}{|c|}{$\begin{array}{c}\text { model (5) } \\
\text { POST IV }\end{array}$}} & \multirow{3}{*}{$\begin{array}{c}\text { model (1) } \\
\text { UN } \\
1019\end{array}$} & \multirow{3}{*}{$\begin{array}{c}\text { model (5) IV } \\
\text { POST IV } \\
1077\end{array}$} \\
\hline & & & & & & & & & & \\
\hline & .739 & $(.0211)$ & .761 & $(.0194)$ & 1380 & $(28)$ & 1416 & $(25.8)$ & & \\
\hline roma tor vergata & .763 & $(.0194)$ & .783 & $(.0183)$ & 1696 & $(30.9)$ & 1498 & $(23.7)$ & 1293 & 1173 \\
\hline roma lumsa & .727 & $(.0377)$ & .701 & $(.0345)$ & 1380 & $(47.2)$ & 1507 & $(47.3)$ & 1003 & 1056 \\
\hline roma luiss & .783 & $(.0364)$ & .802 & $(.035)$ & 1717 & $(61.6)$ & 1661 & $(52.9)$ & 1345 & 1332 \\
\hline roma tre & .809 & $(.0218)$ & .748 & $(.0202)$ & 1423 & $(30.5)$ & 1433 & $(28)$ & 1150 & 1072 \\
\hline cassino & .634 & $(.0367)$ & .629 & $(.0321)$ & 1334 & $(48.8)$ & 1339 & $(41.1)$ & 845 & 842 \\
\hline benevento sannio & .636 & $(.0401)$ & .741 & $(.0385)$ & 1438 & $(54.6)$ & 1408 & $(56.8)$ & 915 & 1043 \\
\hline napoli fedII & .665 & $(.0209)$ & .744 & $(.0249)$ & 1431 & $(33.9)$ & 1430 & $(39.5)$ & 952 & 1064 \\
\hline napoli parthenope & .711 & $(.0419)$ & .750 & $(.0425)$ & 1415 & $(58.8)$ & 1436 & $(61.6)$ & 1007 & 1077 \\
\hline napoli orientale & .603 & $(.048)$ & .687 & $(.0486)$ & 1168 & $(83.7)$ & 1364 & $(102.1)$ & 704 & 936 \\
\hline napoli s orsola & .778 & $(.041)$ & .748 & $(.044)$ & 1155 & $(60.6)$ & 1342 & $(64.5)$ & 898 & 1003 \\
\hline napoli II & .569 & $(.0314)$ & .736 & $(.0354)$ & 1249 & $(54.8)$ & 1361 & $(54.1)$ & 710 & 1002 \\
\hline salerno & .706 & $(.0266)$ & .746 & $(.0294)$ & 1302 & $(35.6)$ & 1394 & $(43.4)$ & 919 & 1040 \\
\hline l'aquila & .806 & $(.0217)$ & .823 & $(.0196)$ & 1456 & $(35.7)$ & 1405 & $(31.1)$ & 1173 & 1157 \\
\hline teramo & .677 & $(.0451)$ & .730 & $(.0427)$ & 1200 & $(71.6)$ & 1278 & $(67.6)$ & 813 & 934 \\
\hline chieti pescara & .754 & $(.0249)$ & .744 & $(.0241)$ & 1494 & $(51.1)$ & 1423 & $(36.2)$ & 1126 & 1058 \\
\hline molise & .710 & $(.0367)$ & .761 & $(.0365)$ & 1299 & $(47)$ & 1377 & $(51.2)$ & 923 & 1048 \\
\hline foggia & .574 & $(.04)$ & .740 & $(.0401)$ & 1313 & $(66.9)$ & 1378 & $(68)$ & 754 & 1020 \\
\hline bari & .700 & $(.023)$ & .792 & $(.0288)$ & 1380 & $(38)$ & 1440 & $(48.2)$ & 966 & 1140 \\
\hline bari politecnico & .887 & $(.0243)$ & .819 & $(.0308)$ & 1600 & $(40.5)$ & 1434 & $(45.6)$ & 1419 & 1175 \\
\hline salento & .648 & $(.0316)$ & .735 & $(.0343)$ & 1249 & $(54)$ & 1385 & $(62)$ & 809 & 1019 \\
\hline basilicata & .750 & $(.0348)$ & .750 & $(.036)$ & 1364 & $(53.3)$ & 1469 & $(60.4)$ & 1023 & 1101 \\
\hline calabria & .671 & $(.0259)$ & .732 & $(.0327)$ & 1282 & $(35.4)$ & 1319 & $(44.3)$ & 861 & 965 \\
\hline catanzaro $\mathrm{m}$ grecia & .586 & $(.0363)$ & .792 & $(.045)$ & 1466 & $(48)$ & 1420 & $(66.3)$ & 859 & 1125 \\
\hline reggio calabria medit & .582 & $(.0387)$ & .680 & $(.0418)$ & 1265 & $(50.4)$ & 1341 & $(64.4)$ & 736 & 911 \\
\hline palermo & .632 & $(.0289)$ & .701 & $(.0291)$ & 1328 & $(37.2)$ & 1423 & $(39.1)$ & 839 & 997 \\
\hline messina & .577 & $(.0232)$ & .694 & $(.0286)$ & 1230 & $(41.8)$ & 1250 & $(45.1)$ & 710 & 867 \\
\hline catania & .640 & $(.0237)$ & .717 & $(.026)$ & 1333 & $(44.2)$ & 1350 & $(46.2)$ & 853 & 968 \\
\hline sassari & .598 & $(.0296)$ & .721 & $(.0271)$ & 1304 & $(41.8)$ & 1416 & $(42.1)$ & 779 & 1020 \\
\hline cagliari & .705 & $(.0219)$ & .757 & $(.0214)$ & 1242 & $(33.5)$ & 1306 & $(34.6)$ & 875 & 989 \\
\hline
\end{tabular}

Note: SE in brackets. Source: IIPL 2007, Istat. 
Table 9: Employment weighted earnings: initial and final rankings (all cycles):1/2

\begin{tabular}{|c|c|c|c|c|c|c|}
\hline \multirow[t]{2}{*}{ University } & \multicolumn{3}{|c|}{ Employment weighted earnings } & \multicolumn{3}{|c|}{ Rankings } \\
\hline & Model (1) & Model (5) IV & diff & Model (1) & Model (5) & diff \\
\hline milano bocconi & 1447 & 1292 & -155 & 2 & 1 & -1 \\
\hline bolzano & 1502 & 1254 & -248 & 1 & 2 & 1 \\
\hline castellanza & 1446 & 1218 & -228 & 3 & 3 & 0 \\
\hline roma luiss & 1142 & 1191 & 48 & 21 & 4 & -17 \\
\hline milano cattolica & 1168 & 1155 & -13 & 14 & 5 & -9 \\
\hline milano & 1093 & 1138 & 45 & 29 & 6 & -23 \\
\hline milano iulm & 1107 & 1130 & 23 & 27 & 7 & -20 \\
\hline milano politecnico & 1358 & 1118 & -241 & 4 & 8 & 4 \\
\hline milano bicocca & 1179 & 1110 & -68 & 12 & 9 & -3 \\
\hline viterbo tuscia & 1343 & 1108 & -235 & 5 & 10 & 5 \\
\hline bergamo & 1198 & 1108 & -90 & 10 & 11 & 1 \\
\hline milano s raffaele & 796 & 1099 & 304 & 52 & 12 & -40 \\
\hline genova & 1149 & 1096 & -52 & 20 & 13 & -7 \\
\hline parma & 1105 & 1086 & -19 & 28 & 14 & -14 \\
\hline bari politecnico & 1151 & 1081 & -70 & 19 & 15 & -4 \\
\hline brescia & 1296 & 1079 & -217 & 7 & 16 & 9 \\
\hline roma tor vergata & 1157 & 1078 & -80 & 17 & 17 & 0 \\
\hline varese insubria & 1160 & 1072 & -88 & 15 & 18 & 3 \\
\hline torino politecnico & 1316 & 1060 & -256 & 6 & 19 & 13 \\
\hline piemonte orientale & 1211 & 1059 & -152 & 9 & 20 & 11 \\
\hline bari & 877 & 1054 & 177 & 49 & 21 & -28 \\
\hline catanzaro $\mathrm{m}$ grecia & 913 & 1053 & 140 & 42 & 22 & -20 \\
\hline napoli parthenope & 884 & 1051 & 167 & 48 & 23 & -25 \\
\hline torino & 1138 & 1049 & -89 & 23 & 24 & 1 \\
\hline trento & 1110 & 1049 & -61 & 26 & 25 & -1 \\
\hline l'aquila & 1122 & 1039 & -83 & 25 & 26 & 1 \\
\hline urbino & 969 & 1035 & 66 & 37 & 27 & -10 \\
\hline pavia & 1037 & 1032 & -6 & 32 & 28 & -4 \\
\hline venezia & 1134 & 1026 & -108 & 24 & 29 & 5 \\
\hline trieste & 1036 & 1023 & -13 & 33 & 30 & -3 \\
\hline
\end{tabular}

Source: IIPL 2007, Istat. 
Table 10: Employment weighted earnings: initial and final rankings (all cycles):2/2

\begin{tabular}{|c|c|c|c|c|c|c|}
\hline \multirow[t]{2}{*}{ University } & \multicolumn{3}{|c|}{ Employment weighted earnings } & \multicolumn{3}{|c|}{ Rankings } \\
\hline & Model (1) & Model (5) IV & diff & Model (1) & Model (5) & diff \\
\hline modena reggio & 1193 & 1021 & -172 & 11 & 31 & 20 \\
\hline roma sapienza & 968 & 1021 & 53 & 38 & 32 & -6 \\
\hline firenze & 1008 & 1013 & 5 & 36 & 33 & -3 \\
\hline udine & 1158 & 1010 & -148 & 16 & 34 & 18 \\
\hline marche politecnica & 1138 & 1010 & -129 & 22 & 35 & 13 \\
\hline macerata & 894 & 1009 & 115 & 46 & 36 & -10 \\
\hline verona & 1170 & 1005 & -165 & 13 & 37 & 24 \\
\hline roma lumsa & 896 & 1001 & 105 & 45 & 38 & -7 \\
\hline napoli fedII & 836 & 997 & 160 & 50 & 39 & -11 \\
\hline roma tre & 947 & 988 & 41 & 39 & 40 & 1 \\
\hline siena & 1157 & 981 & -176 & 18 & 41 & 23 \\
\hline bologna & 1019 & 974 & -45 & 34 & 42 & 8 \\
\hline benevento sannio & 725 & 970 & 245 & 59 & 43 & -16 \\
\hline sassari & 721 & 965 & 244 & 60 & 44 & -16 \\
\hline napoli s orsola & 766 & 965 & 199 & 54 & 45 & -9 \\
\hline molise & 830 & 964 & 134 & 51 & 46 & -5 \\
\hline reggio calabria medit & 652 & 960 & 308 & 65 & 47 & -18 \\
\hline ferrara & 1079 & 957 & -122 & 30 & 48 & 18 \\
\hline camerino & 901 & 955 & 55 & 43 & 49 & 6 \\
\hline basilicata & 759 & 953 & 194 & 57 & 50 & -7 \\
\hline napoli II & 678 & 948 & 270 & 63 & 51 & -12 \\
\hline padova & 1075 & 946 & -129 & 31 & 52 & 21 \\
\hline salento & 671 & 945 & 274 & 64 & 53 & -11 \\
\hline pisa & 1014 & 944 & -69 & 35 & 54 & 19 \\
\hline salerno & 769 & 944 & 175 & 53 & 55 & 2 \\
\hline perugia & 918 & 942 & 24 & 41 & 56 & 15 \\
\hline catania & 766 & 941 & 176 & 55 & 57 & 2 \\
\hline palermo & 900 & 931 & 31 & 44 & 58 & 14 \\
\hline chieti pescara & 1271 & 918 & -353 & 8 & 59 & 51 \\
\hline foggia & 697 & 918 & 221 & 61 & 60 & -1 \\
\hline teramo & 886 & 911 & 25 & 47 & 61 & 14 \\
\hline cagliari & 731 & 896 & 165 & 58 & 62 & 4 \\
\hline calabria & 641 & 896 & 255 & 66 & 63 & -3 \\
\hline venezia iuav & 919 & 877 & -41 & 40 & 64 & 24 \\
\hline messina & 695 & 837 & 142 & 62 & 65 & 3 \\
\hline cassino & 763 & 764 & 1 & 56 & 66 & 10 \\
\hline napoli orientale & 495 & 757 & 262 & 67 & 67 & 0 \\
\hline
\end{tabular}

Source: IIPL 2007, Istat. 
Table 11: Other rankings

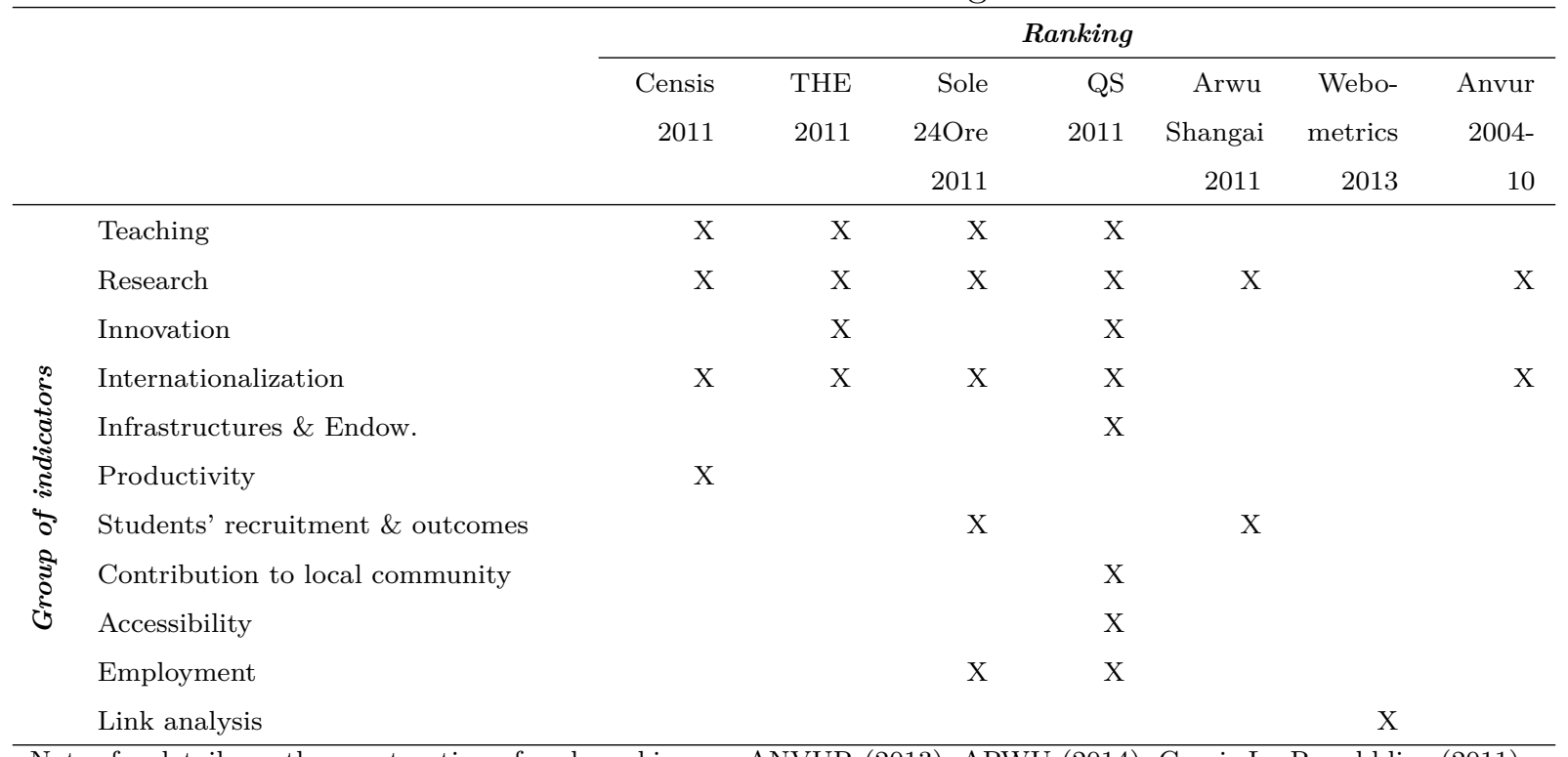

Note: for details on the construction of each ranking see ANVUR (2013), ARWU (2014), Censis-La Repubblica (2011),

Thomson Reuters-Times (2011), QS(2011), Webometrics (2014)

Table 12: Spearman's rank correlation coefficient across rankings

\begin{tabular}{lrrr}
\hline Ranking & model (1) & model (5) IV & $\begin{array}{r}\text { \# universities } \\
\text { compared }\end{array}$ \\
\hline model (1) & 1 & $0.72^{* * *}$ & 67 \\
model (5) IV & $0.71^{* * *}$ & 1 & 67 \\
Censis 2011 & $0.28^{* *}$ & 0.13 & 57 \\
THE 2011 & 0.07 & 0.14 & 14 \\
Sole 24 Ore 2011 & $0.63^{* * *}$ & $0.47^{* * *}$ & 64 \\
QS 2011 & -0.15 & -0.04 & 18 \\
Arwu-Shangai2011 & -0.20 & -0.14 & 21 \\
Webometrics2013 & $0.21^{*}$ & 0.01 & 67 \\
Anvur 2004-10 & $0.43^{* * *}$ & $0.28^{* *}$ & 67 \\
\hline & Note: ${ }^{* * *}=\mathrm{p}<0.01 ; * *=\mathrm{p}<0.05 ;$ & $* \mathrm{p}<0.1$. &
\end{tabular}

For model (1) and (5) IV employment weighted earnings, all cycles. Source: IIPL 2007, Istat. 
Figure 1. Changes in predicted employment across models.

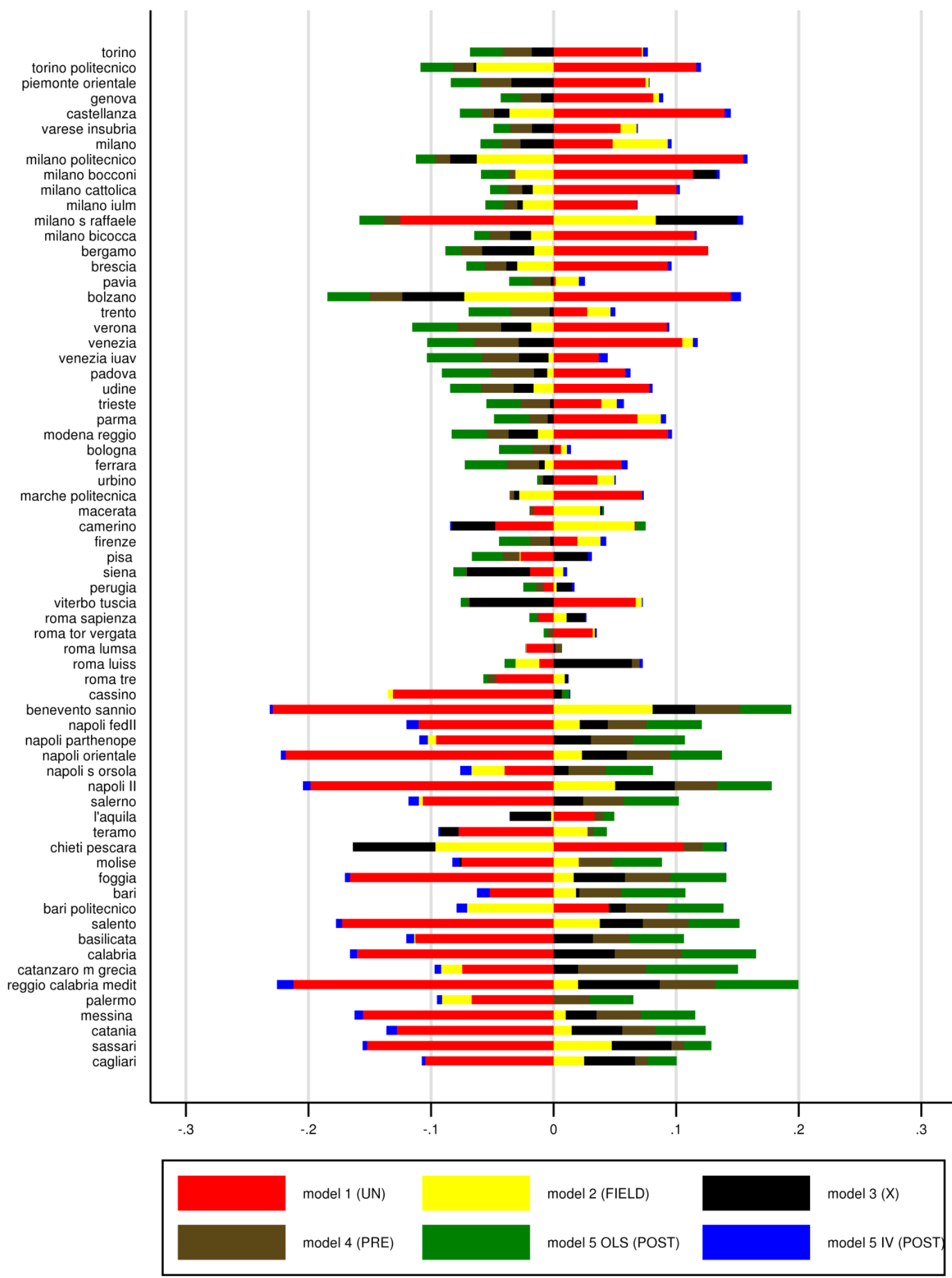

Note: All cycles. Each bars represents the difference of predicted employment w.r.t. the previous model. For the first model (red bars), the difference is taken w.r.t. the grand mean. Source: IIPL, 2007, Istat. 
Figure 2. Employment ranking

(Predicted employment across universities: model (1) and model (5) IV

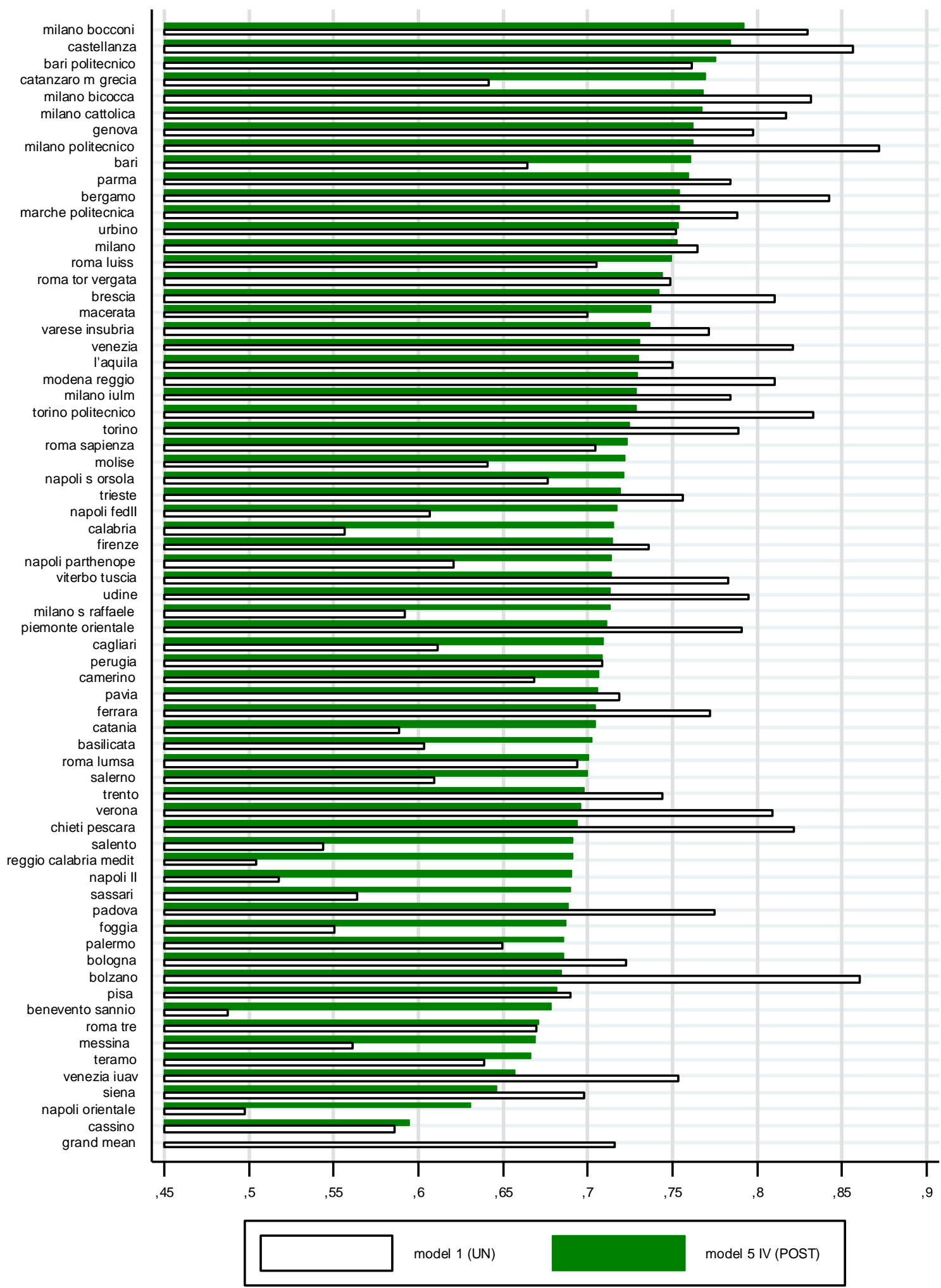

Note: All cycles. Source : IIPL, 2007, Istat. 
Figure 3. Earnings ranking

(Predicted earnings across universities: model (1) and model (5) IV)

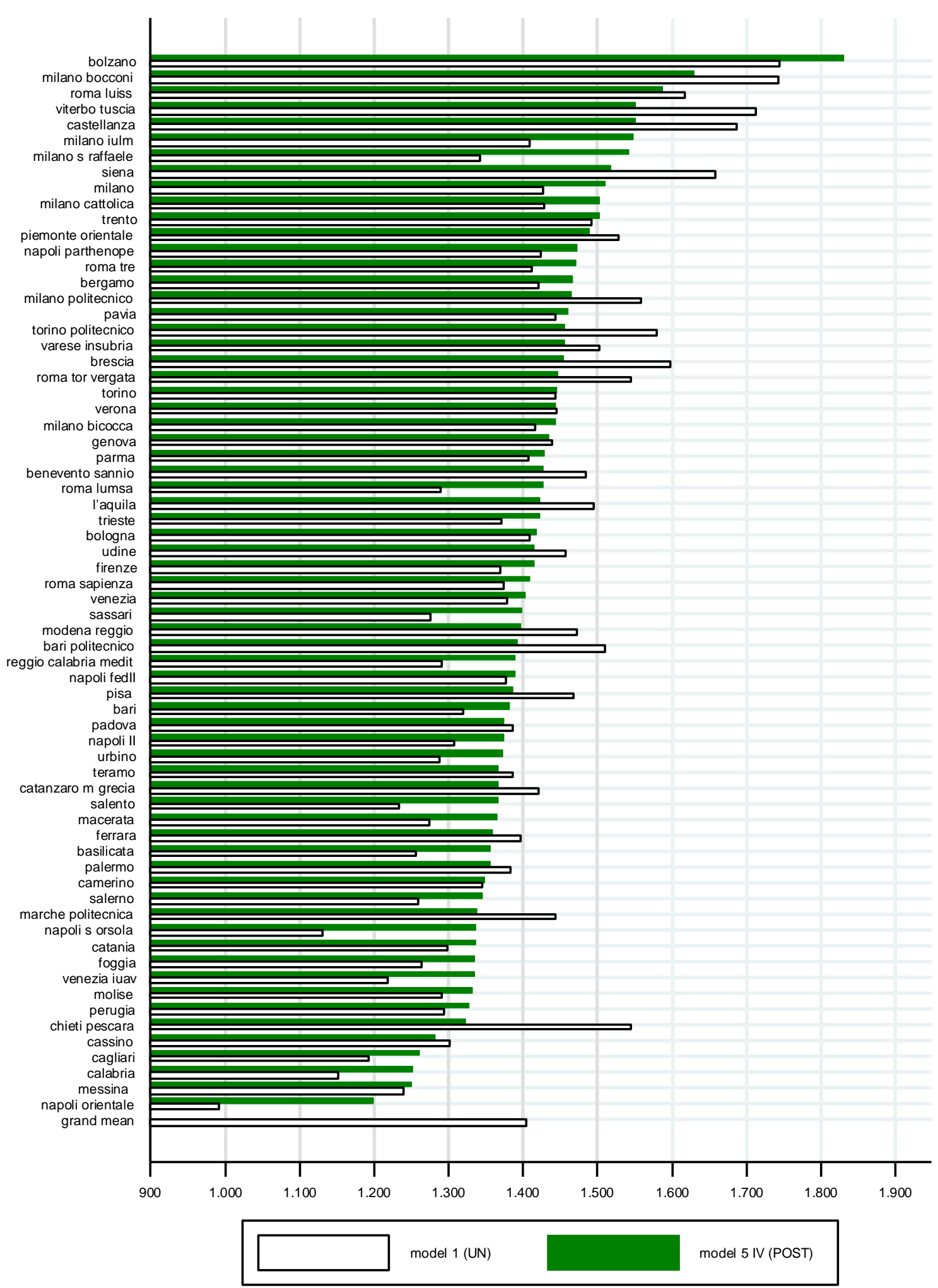

Note: All cycles Source: IIPL, 2007, Istat 
Figure 4. Employment Weighted Earnings Ranking

\section{(Predicted weighted earnings across universities: model (1) and model (5) IV}

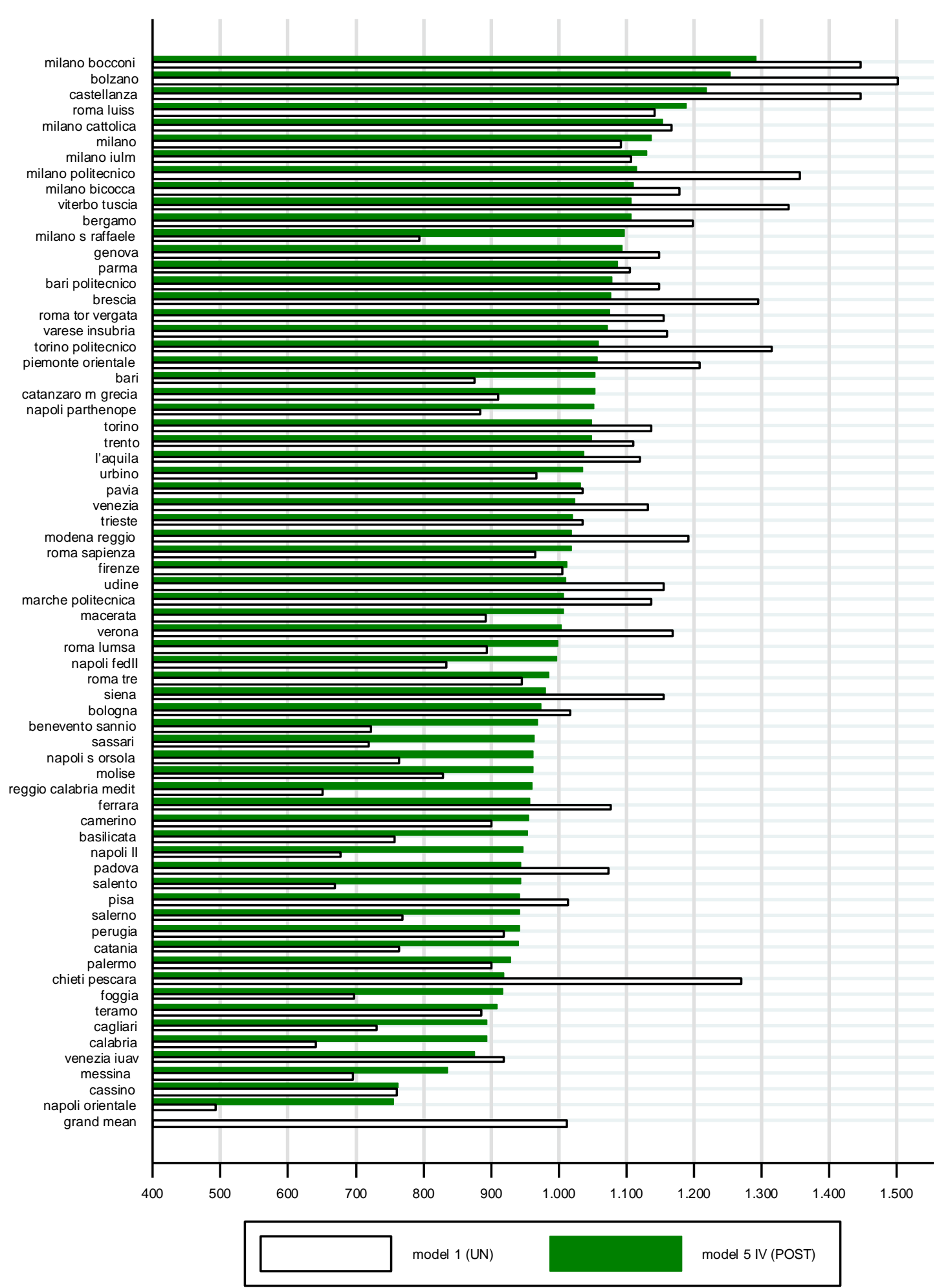

Note: All cycles Source: IIPL, 2007, Istat. 
Figure 5. Employment weighted earnings by area of the university and model

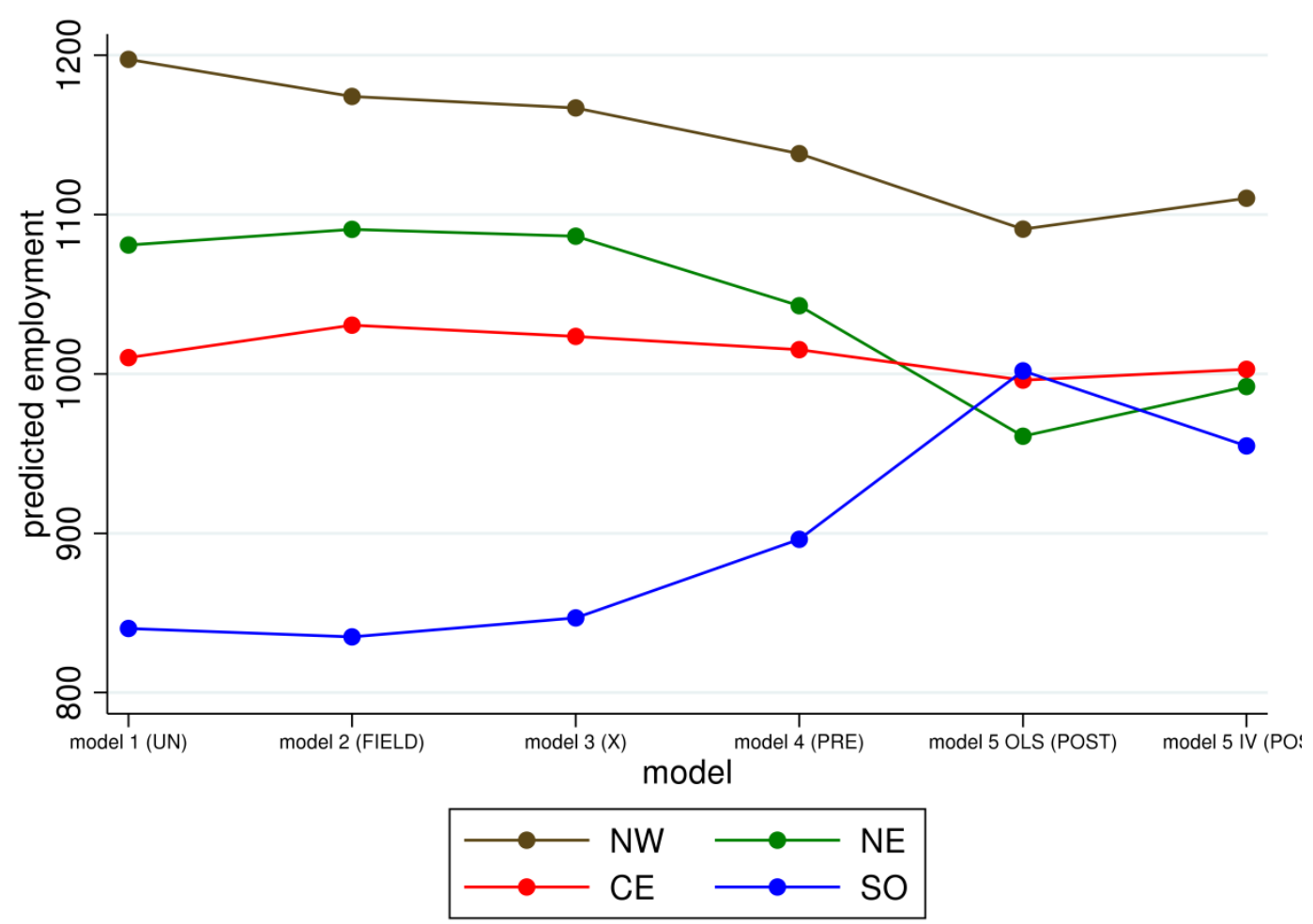

Note: All cycles. Source: IIPL, 2007, Istat. 
Figure 6. First and second cycle: predictions for employment and earnings (model 5 IV)

(a) Employment

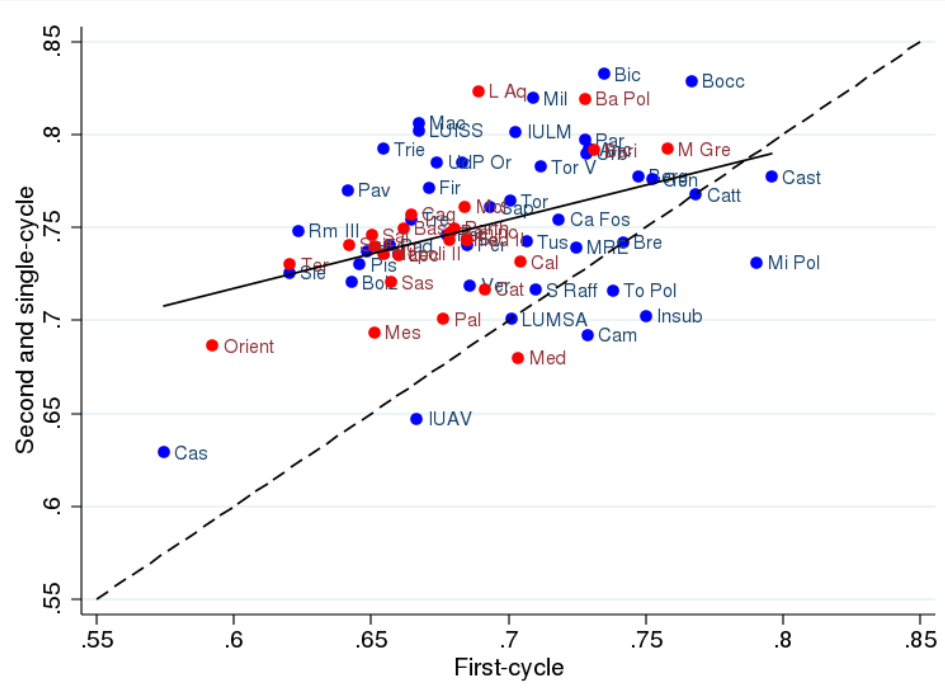

(b) Earnings

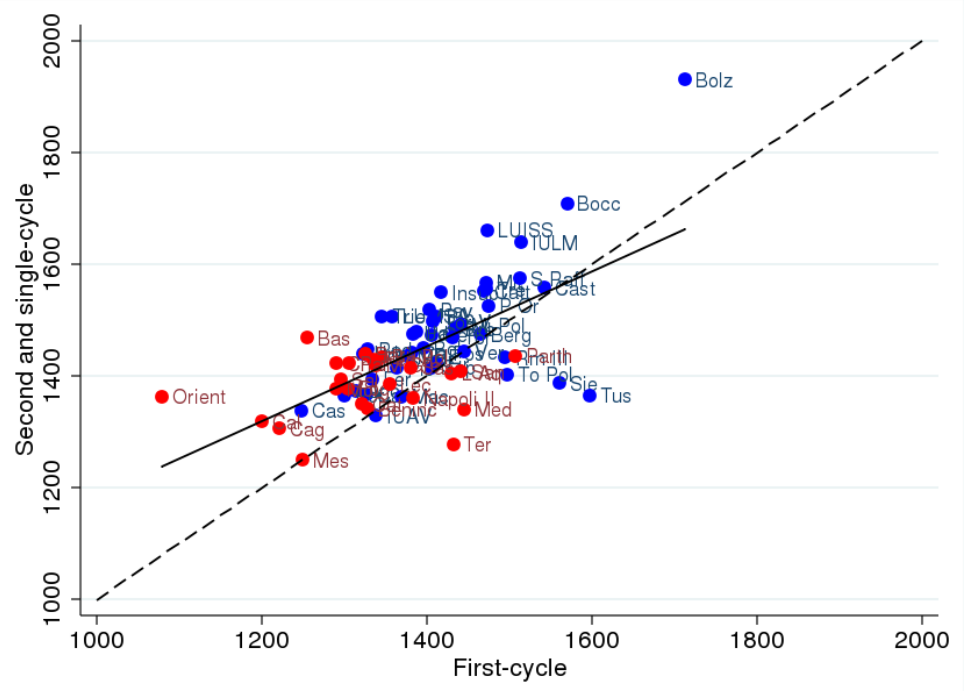

Note: the red marker indicates universities located in the South. The blue marker indicates universities located in other areas. Source: IIPL, 2007, Istat

Figure 7. Predicted earnings and predicted employment by cycle (model 5 IV)

(a) First cycle

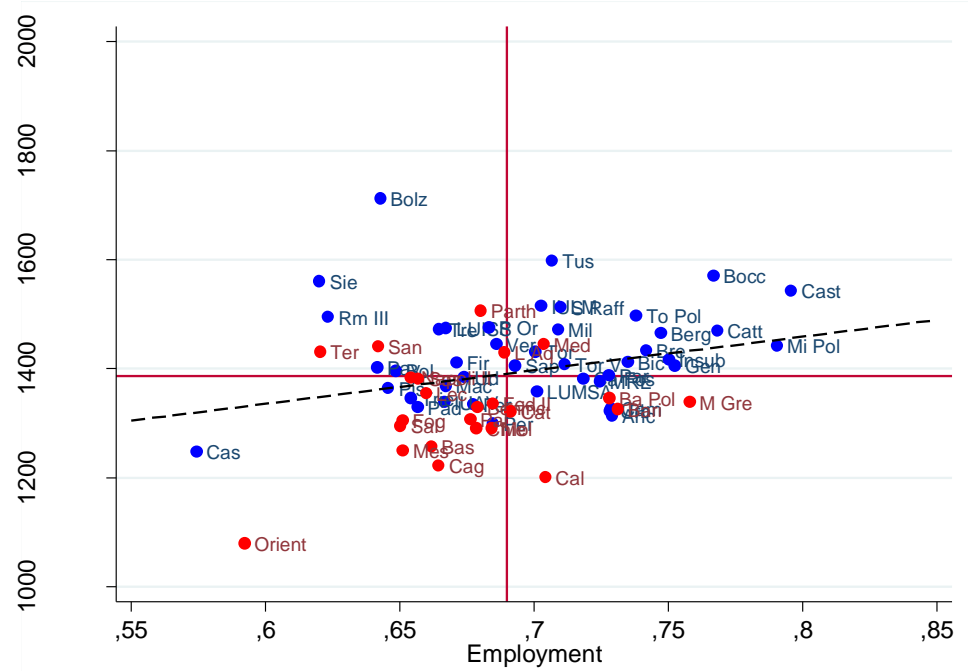

(b) Second and single cycle

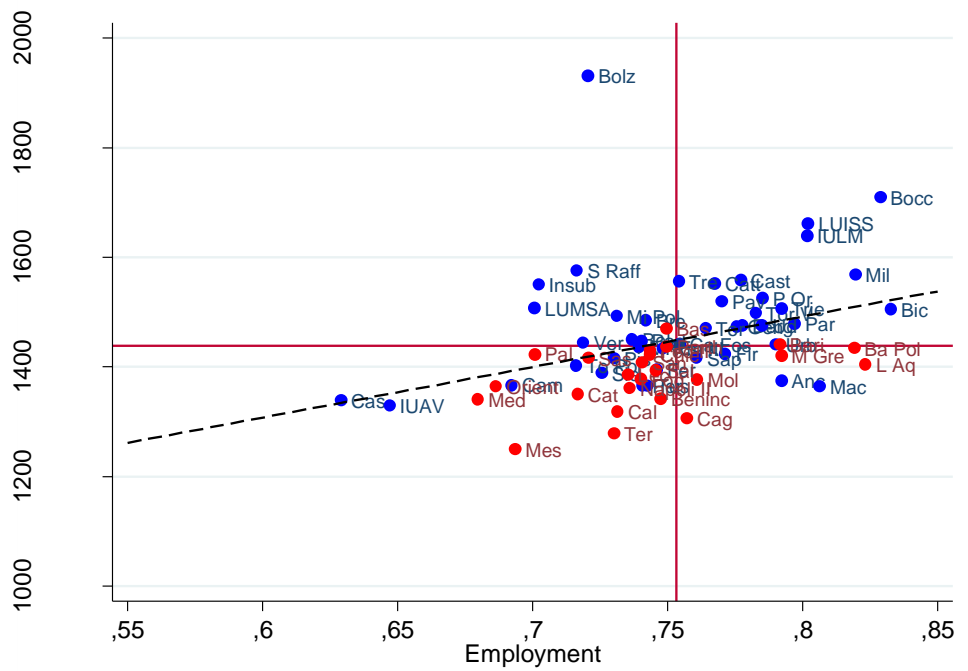

Note: the red marker indicates universities located in the South. The blue marker indicates universities located in other areas. The vertical and horizontal line indicates the mean of the variable in each axis. Source: IIPL, 2007, Istat. 
Figure 8. Robustness

(a) Predicted Employment: Model 3 versus model Model3+ Post-graduation educational observables

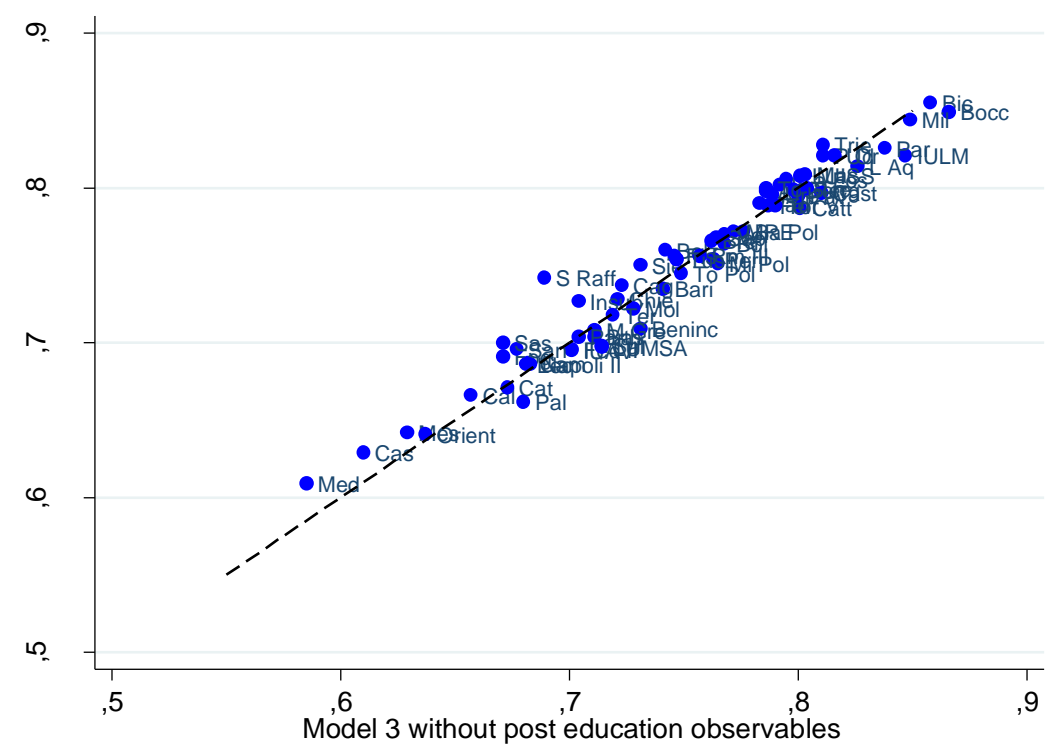

Note: on the vertical axis, predicted employment from model 3. On the horizontal axis the predicted employment of model 3, without post-graduation educational observables. Pearson's $r=0.977$; Spearman's rho $=0.974$. Second and single cycle. Source: IIPL, 2007, Istat

\section{(b) Predicted Employment: the impact of including international}

$$
\text { migrants (all cycles) }
$$

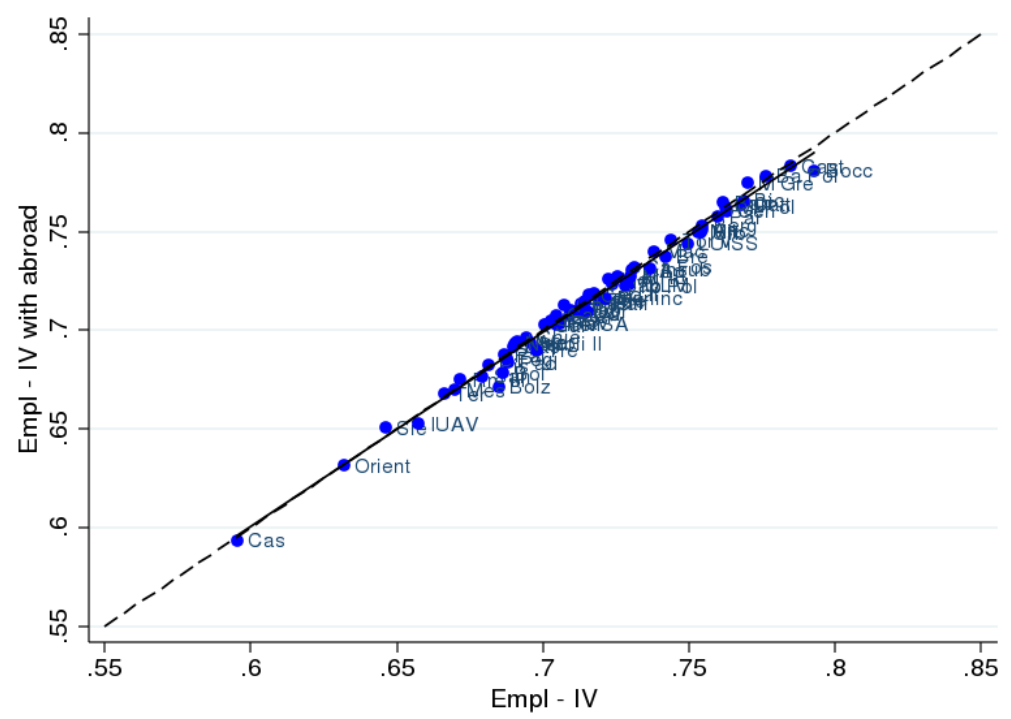

Note: on the horizontal axis, predicted employment from model 5 IV. On the vertical axis predicted employment from a model where graduates from abroad and working abroad are not removed. In that model, a dummy is introduced for thos workers. Pearson's $r=0.995$; Spearman's rho $=0.995$. All cycles. Source: IIPL, 2007, Istat 
(c) Predicted Employment: linear and probit models (all cycles)

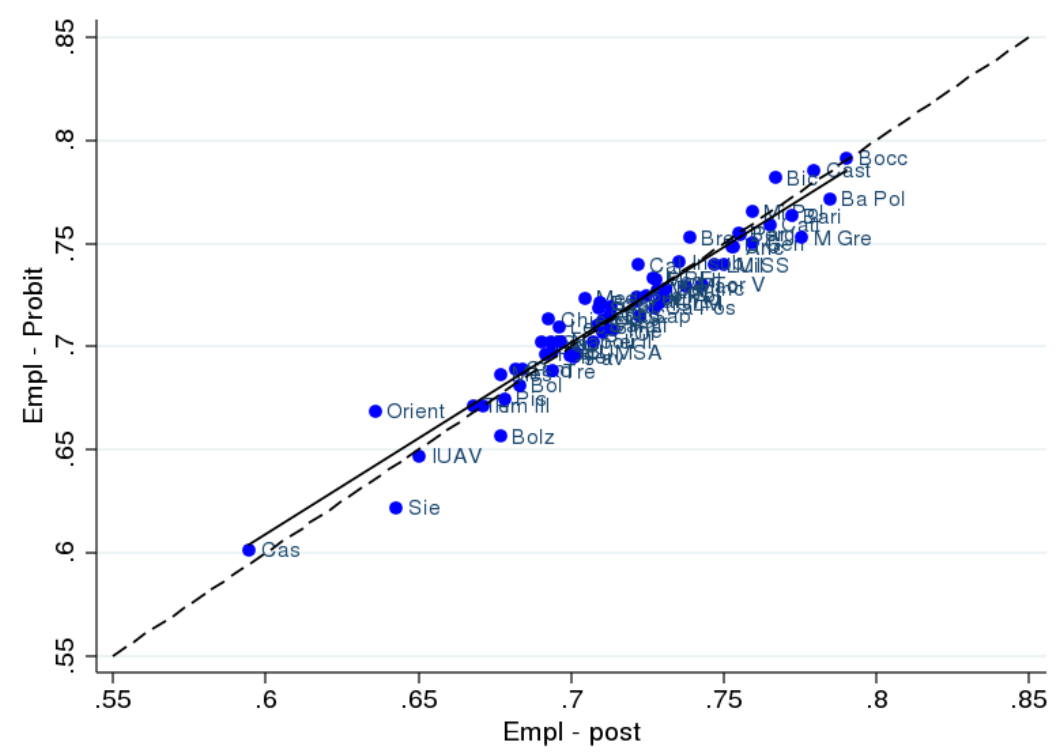

Note: on the horizontal axis, predicted employment from model 5 OLS. On the vertical axis predicted employment from the corresponding probit specification. Pearson's $r=0.964$; Spearman's rho $=0.963$. All cycles. Source: IIPL, 2007, Istat

(d) Predicted Employment: the impact of missing earnings (all cycles)

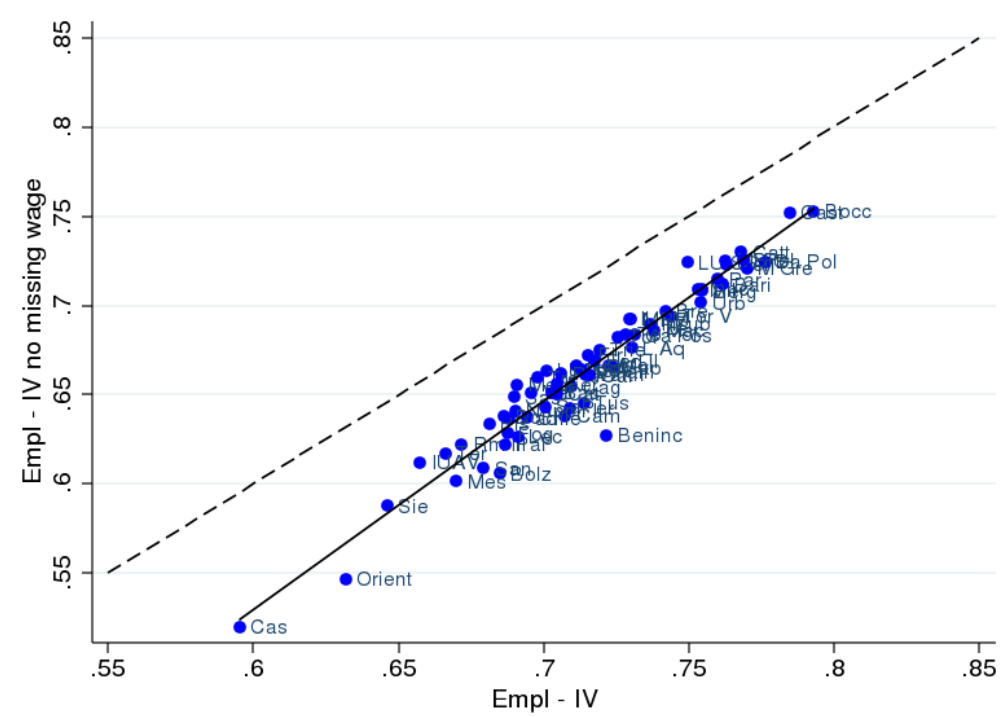

Note: on the horizontal axis, predicted earnings from model 5 IV. On the vertical axis predicted earnings from model 5 IV on a sample with non-missing earnings. Pearson's $r=0.970$; Spearman's rho $=0.956$. All cycles. Source: IIPL, 2007, Istat 
(e) Predicted earnings: linear and Poisson models

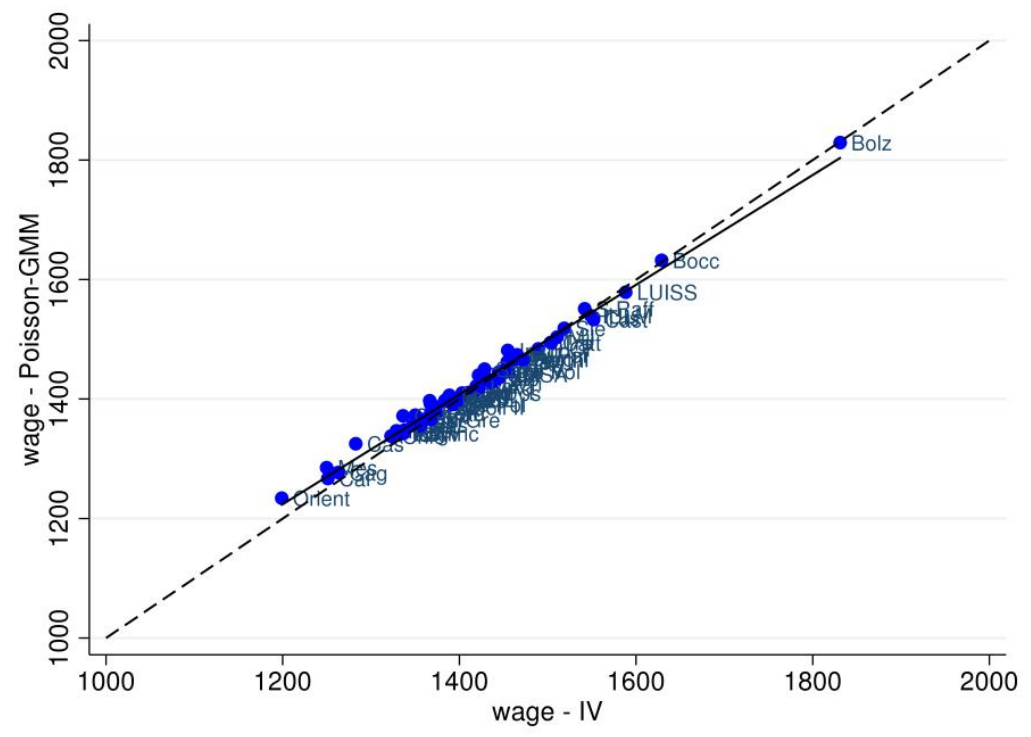

Note: on the horizontal axis, predicted earnings from model 5 IV. On the vertical axis predicted earnings from the corresponding Poisson-GMM specification. Pearson's $r=0.993$; Spearman's rho $=0.989$. All cycles. Source: IIPL, 2007, Istat 
Figure 9. Robustness: Predicted employment weighted earnings across universities

(red bars: employment is calculated only non-missing earnings units)

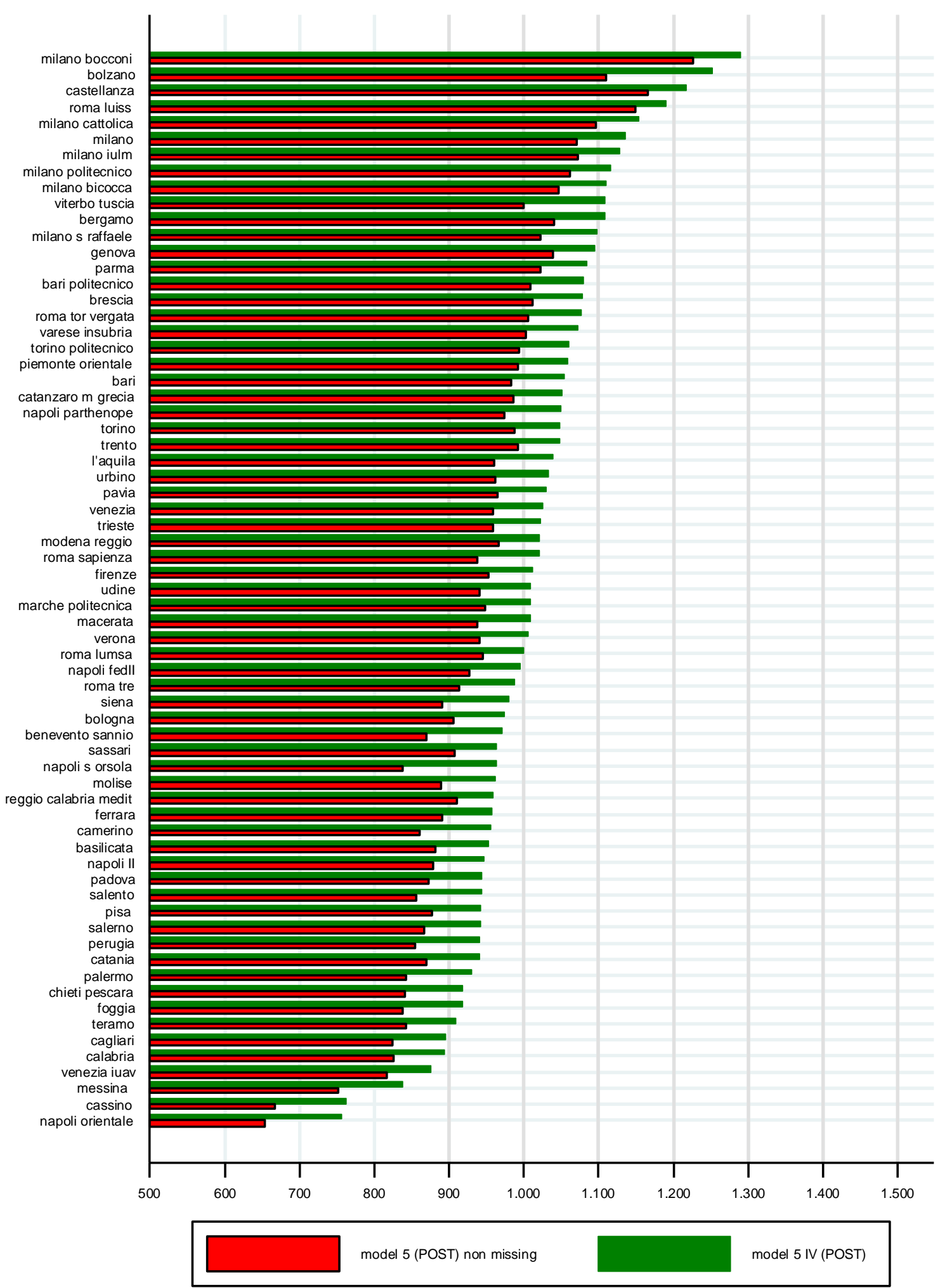

Note: All cycles. Source: IIPL, 2007, Istat. 